\title{
SAYWAS Y GEOGRAFÍA SAGRADA EN EL QHAPAQ ÑAN DEL DESPOBLADO DE ATACAMA ${ }^{1}$
}

\author{
SAYWAS AND SACRED GEOGRAPHY IN THE QHAPAQ NAN OF THE \\ DESPOBLADO DE ATACAMA
}

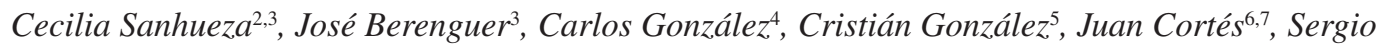 \\ Martín $^{6,8}$ y Jimena Cruz ${ }^{9}$
}

\begin{abstract}
Se presentan nuevos resultados de nuestra investigación etnohistórica, arqueológica y astronómica en el Qhapaq Ñan del Despoblado de Atacama, específicamente en la cuenca del salar de Punta Negra. Se registran y analizan dos conjuntos de saywas (Tocomar y Vaquillas), sus contextos asociados y las características generales del camino en los sectores estudiados. En ambos casos se comprueba el alineamiento con la salida del sol el día del solsticio de invierno y del equinoccio respectivamente. Desde una perspectiva temporal y espacial, se desarrolla una discusión interdisciplinaria respecto a estas localidades y estructuras, y a sus significados. A la luz de los nuevos antecedentes recogidos, se retoman también análisis y propuestas anteriores sobre el Qhapaq Ñan del Despoblado, las saywas astronómicas, el entorno geográfico y la construcción simbólica de un espacio sagrado y de una cartografía oral imperial.
\end{abstract}

Palabras claves: Qhapaq Ñan, desierto de Atacama, saywas, arqueoastronomía, geografía sagrada.

This paper presents new results of our ethnohistorical, archaeological, and astronomical research in the Qhapaq Ñan of the Despoblado of Atacama, specifically in the Punta Negra salt basin. Two sets of saywas-Tocomar and Vaquillas-, their associated contexts, and the general characteristics of the road in the studied sectors, were recorded and analyzed. In both cases, alignment with the sunrise on the day of the winter solstice and the equinox, respectively, was checked. From a temporal and spatial perspective, an interdisciplinary discussion is presented on these localities and structures, as well as their meanings. Furthermore, the new information collected allows for resuming previous analyzes and proposals on the Qhapaq Nan of the Despoblado, the astronomical saywas, the geographical environment, and the symbolic construction of a sacred space and an imperial oral cartography.

Key words: Qhapaq Ñan, Atacama Desert, saywas, archaeoastronomy, sacred geography.

En las últimas décadas la vialidad inkaica de la región conocida desde tiempos coloniales como el Despoblado de Atacama, ha sido objeto de numerosos estudios (González 2017; Hyslop 1984; Lynch 199596; Lynch y Núñez 1994; Molina 2018; Niemeyer y Rivera 1983; Núñez, P. 1981; Sanhueza 2005, 2017). Como resultado, se cuenta en la actualidad con un registro de campo bastante avanzado, aunque varios tramos aún no han sido abordados sistemáticamente.
Un hallazgo inesperado que ha producido el estudio de la vialidad estatal en el desierto atacameño, son las saywas o hitos de piedra que se ubican a ambos lados del camino y que hemos identificado hasta el momento en seis sitios diferentes, correspondientes a Ramaditas (SV-14) (Berenguer et al 2005; Sanhueza 2017), Camar (CA-01 A y B), Tocomar (TO-02 A y B) y Vaquillas (VA-01 A, B, C y D) (Sanhueza 2012, 2017). La arqueología de las décadas anteriores las

\footnotetext{
${ }^{1}$ Una primera versión de este trabajo fue presentada en el Qhapaq Ñan II, Taller Internacional en torno al Sistema Vial Inkaico (24-27 de octubre de 2017), efectuado en Salta, Argentina. Este manuscrito fue evaluado por pares externos y editado por el Comité Editorial de Chungara y los editores invitados Carlos González y Christian Vitry.

${ }^{2}$ Universidad Bernardo O’Higgins, Centro de Estudios Históricos, Santiago, Chile. csanhueza@ hotmail.com

${ }^{3}$ Museo Chileno de Arte Precolombino, Santiago, Chile. jberenguer@museoprecolombino.cl

${ }^{4}$ Instituto de Investigación en Ciencias Sociales y Educación, Universidad de Atacama, Copiapó Chile. carlos.gonzalezg@uda.cl

${ }^{5}$ Institute of Archaeology, University College London, Londres, UK. c.gonzalez-rodriguez@ucl.ac.uk

${ }^{6}$ Joint ALMA Observatory, Santiago, Chile. Juan.cortes@alma.cl; Sergio.martin@alma.cl

${ }^{7}$ National Radio Astronomy Observatory, Santiago, Chile.

${ }^{8}$ European Southern Observatory, Santiago, Chile.

${ }^{9}$ Instituto de Investigaciones Arqueológicas y Museo R.P. Gustavo Le Paige, Universidad Católica del Norte, San Pedro de Atacama, Chile.jcruz@ucn.cl
} 
llamó "topus" o "tupus" (Niemeyer y Rivera 1983; Núñez, P. 1981), "hitos" (Berenguer et al. 2005; Lynch 1995-96; Niemeyer y Rivera 1983), "marcas" (Lynch y Núñez 1994), "amojonamientos" (Castro et al. 2004), "columnas de piedras" y "stone piles" (Hyslop 1984). Inicialmente los autores plantearon que podría tratarse de sistemas de medición de distancias o "leguas del Inka" de acuerdo a lo señalado por fuentes españolas e indígenas de la época (Bertonio 1984; Sanhueza 2004). Sin embargo, la distribución de estas estructuras en el camino parecía ser arbitraria, no había regularidad en la ubicación de los hitos o en la distancia que los separaba, lo que hizo a los investigadores descartar esa idea concluyendo que eran señalizadores del camino.

En una publicación anterior discutimos posibles interpretaciones del término tupu, utilizado por algunos cronistas como unidad de medición de distancias, especialmente por su carácter multifactorial, relativo y flexible, concluyendo que este tipo de marcadores más que "medir" en un sentido occidental contemporáneo, estaría dando cuenta de una previa negociación política y ritual para la demarcación de deslindes políticos y de derechos territoriales, incluso en el propio camino del Inka (Sanhueza 2004). Por otra parte, si bien no era convincente que estos dispositivos de piedra indicaran distancias, el calificativo de tupu refería a un acto de medición que, más que estrictamente espacial, parecía ser temporal. La orientación de las saywas respecto al camino del Inka, las diferencias entre ellas, la cantidad, ubicación y distancias que presentaban unas de otras en un mismo sitio, abrieron la posibilidad de que se tratara de alineamientos astronómicos. Efectivamente, las saywas del Inka estaban estrechamente asociadas al culto solar y a la medición del tiempo calendárico. Acuñamos el término saywa para denominarlas ya que en los antiguos vocabularios quechuas y aymaras es definido como "mojón" o "lindero" de tierras y de caminos inkas, pero también es sinónimo de ticnu "el zenit o punto de la mitad del cielo" (Bertonio 1984; Santo Tomás 1951 [1560]; González Holguín 1952). Por otra parte, "sayba" es el término que utiliza Polo de Ondegardo en el siglo XVI, para referirse a las columnas astronómicas del Cusco que señalaban solsticios, equinoccios y las estaciones del año (Bauer y Dearborn 1998:45) ${ }^{1}$.

Esta investigación comienza en 2002 con el hallazgo de las saywas de Ramaditas (Río Loa), identificadas como SV14 en el proyecto Fondecyt 1010327 (Berenguer et al. 2005; Sanhueza 2017). A partir de allí se fueron identificando nuevos sitios, en su mayoría previamente descritos arqueológicamente. En 2012, con ayuda de los astrónomos de ALMA Juan Cortés y Sergio Martín, coautores de este artículo, obtuvimos los primeros resultados favorables a la existencia de alineamientos astronómicos en fechas de solsticios y equinoccios. Sin embargo, en algunos casos este alineamiento era dudoso, lo que podía deberse a la presencia de accidentes geográficos en el horizonte como lomas o montañas que podían alterar los resultados. Por ello se hizo indispensable la observación presencial y el registro fotográfico de esos eventos solares. En ese contexto se pudo registrar y confirmar el alineamiento de las saywas de Ramaditas (Río Loa) con el solsticio de invierno el 21 de junio de 2014 (Sanhueza 2017). Sin embargo, en los otros casos estudiados, por tratarse de saywas ubicadas en localidades de difícil acceso dentro del Despoblado de Atacama, esta nueva etapa requirió de apoyo financiero, de una planificación que permitiera asistir a estas localidades en las fechas precisas, y de la conformación de un equipo multidisciplinario compuesto por historiadores, arqueólogos, astrónomos e investigadores atacameños.

En este artículo se presentan nuevos resultados de la investigación en el Despoblado a través de la verificación y registro de dos conjuntos de saywas, como también de sus contextos asociados, poniendo la atención en el trazado y las características del camino inka en los sectores inmediatos de las saywas. Entre 2017 y 2018, se revisitaron las saywas de los sectores de Tocomar (Salar de Punta Negra) y de Vaquillas (junto a la quebrada El Calvario, en el sector meridional de la cuenca del salar de Punta Negra), y se realizó una prospección en la quebrada de Río Frío, que ha sido documentada por las fuentes históricas como punto de paso del camino inka, y cuya tradición oral y toponimia asociada ha arrojado algunas luces respecto a la mirada estatal de esta región del Despoblado (Sanhueza 2005, 2012) (Figura 1). Por otra parte, nos proponemos desarrollar una reflexión y discusión de carácter más interpretativo y propositivo respecto a estas localidades y estructuras, sus contextos y sus significados desde una perspectiva temporal y espacial o territorial. Incluimos y retomamos discusiones anteriores sobre las saywas y sobre esta zona del Despoblado que, a la luz de los nuevos antecedentes, adquieren mayor significación y sentido (Berenguer 2007; Sanhueza 2005, 2012).

Metodológicamente, una primera fase de la investigación consistió en la georreferenciación digital de los puntos de interés descritos en la literatura científica, y en la sistematización de los registros efectuados por expediciones anteriores, no todas publicadas. En terreno se realizó el reconocimiento y prospección arqueológica de los lugares mencionados, efectuando un recorrido vehicular y pedestre no sistemático que permitió identificar varios segmentos del Qhapaq Ñan. Además, se registraron 25 sitios arqueológicos que incluyen saywas, hitos camineros, pequeños refugios y otros asentamientos o estructuras medianas o menores que, si bien son anteriores al Qhapaq Nan, parecen haber sido utilizados, y en la práctica incorporados a la red vial estatal, aprovechando la infraestructura 

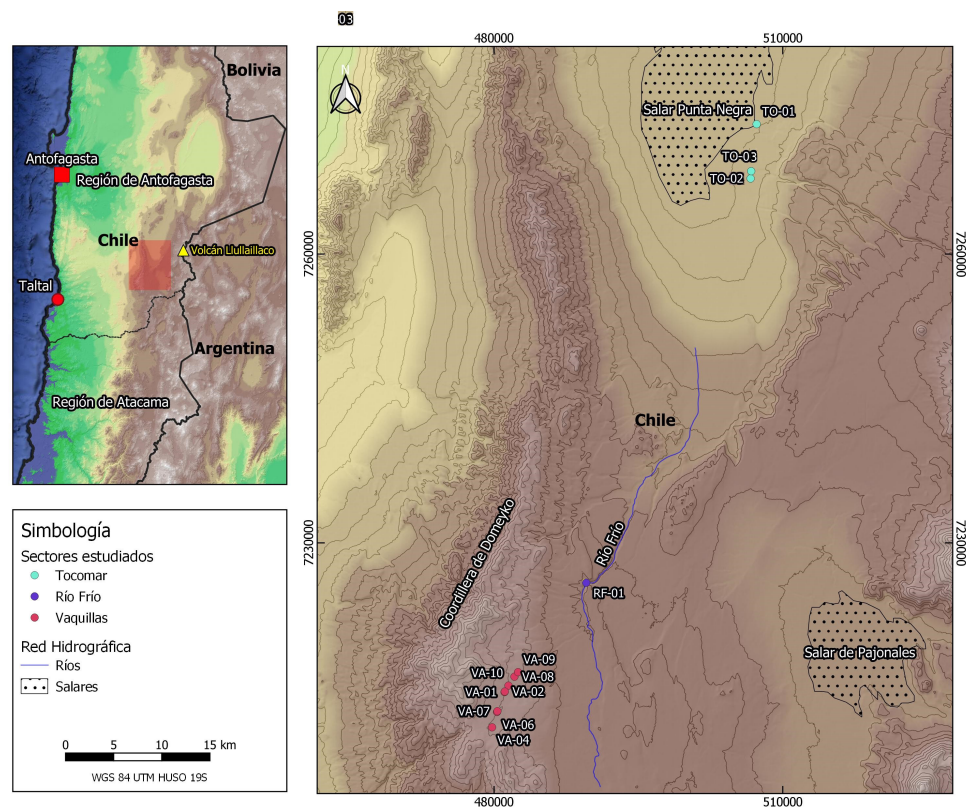

Figura 1. Mapa del área de estudio con la ubicación de los sitios mencionados en el texto.

Map of the study area with the location of the sites mentioned in the text.

expeditiva disponible (Berenguer y Salazar 2017). Este material fue sistematizado y complementado con la información astronómica, etnohistórica y etnográfica disponible.

\section{El Qhapaq Ñan del Despoblado de Atacama}

El camino inkaico del Despoblado se caracteriza por atravesar la región más árida del desierto de Atacama. Tradicionalmente, lo que los españoles denominaron el Gran Despoblado de Atacama, comprendía aproximadamente desde el sur del Salar de Atacama hasta el valle de Copiapó, abarcando unos $500 \mathrm{~km}$ de distancia (Sanhueza 2005). En lo que podríamos denominar un primer gran trayecto del camino, que corresponde a un extenso recorrido de aproximadamente $230 \mathrm{~km}$ (entre las localidades de Peine al norte y el Portezuelo de Vaquillas al sur), la cota promedio de altura es de unos $3.000 \mathrm{msm}$, abarcando incluso varios kilómetros con alturas superiores a los $4.000 \mathrm{msm}$. A pesar de sus condiciones de extrema aridez, esta ruta ascendente articulaba una secuencia de asentamientos menores, y estaba trazada en la franja de transición entre precordillera y puna, permitiendo la captación de recursos de agua, forraje y fauna silvestre (Niemeyer y Rivera 1983). Como en otras regiones, el camino estatal se superpuso a rutas de desplazamiento muy anteriores utilizadas por las poblaciones del Salar de Atacama, del Valle de Copiapó, de la puna aledaña y las regiones adyacentes (González y Westfall 2005; Niemeyer y Rivera 1983). Convencionalmente, el camino del Despoblado se inicia hacia el sur desde el tambo de Peine ubicado en el borde suroriental del salar de Atacama, bordea los oasis de Tilomonte y Tilopozo, atraviesa la Sierra de Tambillo y continúa por una meseta flanqueada al oeste por la Cordillera de Domeyko. En esta latitud este cordón montañoso se extiende en forma paralela a los Andes, pero más al sur comienza a cerrarse hacia el este, alcanzando o encontrándose con el macizo andino aproximadamente a la altura del Portezuelo de Vaquillas (Niemeyer y Rivera 1983; Sanhueza 2005). En todo el tramo previo a Vaquillas, el camino está enmarcado al poniente por Domeyko y al oriente por el piedemonte de la Cordillera de los Andes. Luego de la Sierra de Tambillo, el camino continúa oscilando en alturas promedio de $3.000 \mathrm{msm}$, hasta alcanzar la gran cuenca del Salar de Punta Negra. Los cerca de 100 $\mathrm{km}$ que hay entre el extremo norte del Salar de Punta Negra y el extremo sur de la cuenca, en el Portezuelo de Vaquillas, constituyen el trayecto más seco, inhóspito y solitario atravesado por el Qhapaq Nan en todo los Andes. Aun así, en los últimos 40 años no ha habido década en que no se haya realizado alguna expedición a este remoto camino del Desierto de Atacama (Advis 2008; Gedda 1995; Hyslop 1984; Lynch 1995-96; Lynch y Núñez 1994; Molina 2018; Niemeyer y Rivera 1983; Núñez P. 1981; Sanhueza 2005, 2017; Sinclaire 2005, 2006). En la mayoría de estos casos se recorrió la 
ruta que bordea el lado oriental del Salar de Punta Negra, para luego alcanzar en dirección sudoeste la localidad de Río Frío y finalmente los Llanos de Vaquilla Alta, hasta llegar al portezuelo. A continuación, describimos de norte a sur, los sectores de Tocomar, Río Frío y Vaquillas, incluyendo la información aportada por esas expediciones, e incorporando nuestros hallazgos y conclusiones en torno a la ruta del Inka y en particular a las saywas estudiadas.

\section{Sector Tocomar}

El sitio de Tocomar (3.050 msm) está ubicado a unos $150 \mathrm{~km}$ al sur del poblado de Peine, en la orilla sur del Salar de Punta Negra en un paraje completamente deshabitado y desprovisto de vegetación, pero con pajonales en el borde oriental del salar y presencia de ojos de agua salobre. Su nombre es el de una amplia quebrada que desciende de la Cordillera de los Andes y desemboca en el salar al sur de Cerro de Punta Negra $(3.560 \mathrm{~m})$. Al oeste corre con orientación meridiana la Cordillera de Domeyko, donde destacan las cumbres Cerro Chinchilla (3.594 m) y Cerro Alto de Varas (4.336 m) y al este la Cordillera de los Andes, donde sobresale el Volcán Llullaillaco (6.739 m), el tercero de mayor altura en Chile (Figura 2).
Pese a las citadas expediciones, el trayecto del Qhapaq Nan correspondiente al Salar de Punta Negra presenta notorios vacíos de información. Excepto un camino que va al Volcán Llullaillaco, Niemeyer y Rivera (1983:195, 148-150; véase también Núñez 1981:56) no registran casi ningún sitio en los $41 \mathrm{~km}$ que separan a Quebrada Zorras de Guanaqueros (al norte) y Barrancas Blancas (al sur). Lo mismo ocurre con la expedición de Al Sur del Mundo en los $120 \mathrm{~km}$ que median de sur a norte entre Río Frío y Tambo Meteorito (Gedda 1995), y con la expedición de Molina, que no reporta sitios en la Pampa Tocomar, la quebrada homónima y la orilla del salar al norte y sur de esta colada basáltica (Sinclaire 2006). Tales vacíos sugieren que estas expediciones circularon por cotas más elevadas. Sin embargo, una fotografía de Thomas Lynch (1995-96: fig. 16) que por primera vez registra dos hitos inkaicos destruidos (saywas) en Tocomar, confirma que al menos este investigador sí recorrió la "ruta baja". Siguiendo sus referencias generales y basándonos en la fotografía mencionada, pudimos dar por primera vez con este sitio el año 2009, en una expedición no publicada en la que participaron Marinka Núñez, Pablo Mignone y Cecilia Sanhueza. Posteriormente, en 2017, registramos en el sector de Tocomar distintos tipos de elementos arquitectónicos
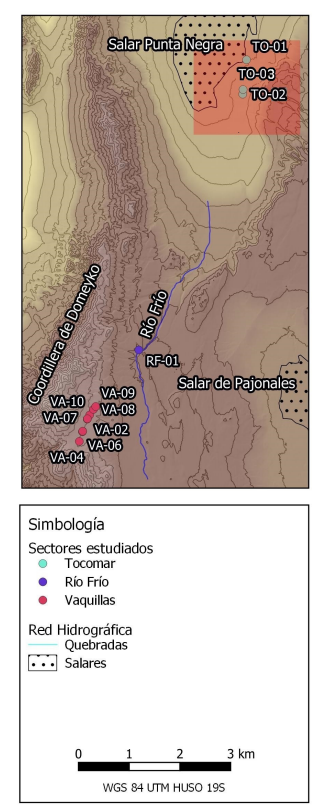

Figura 2. Sector Tocomar. Tocomar sector

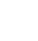

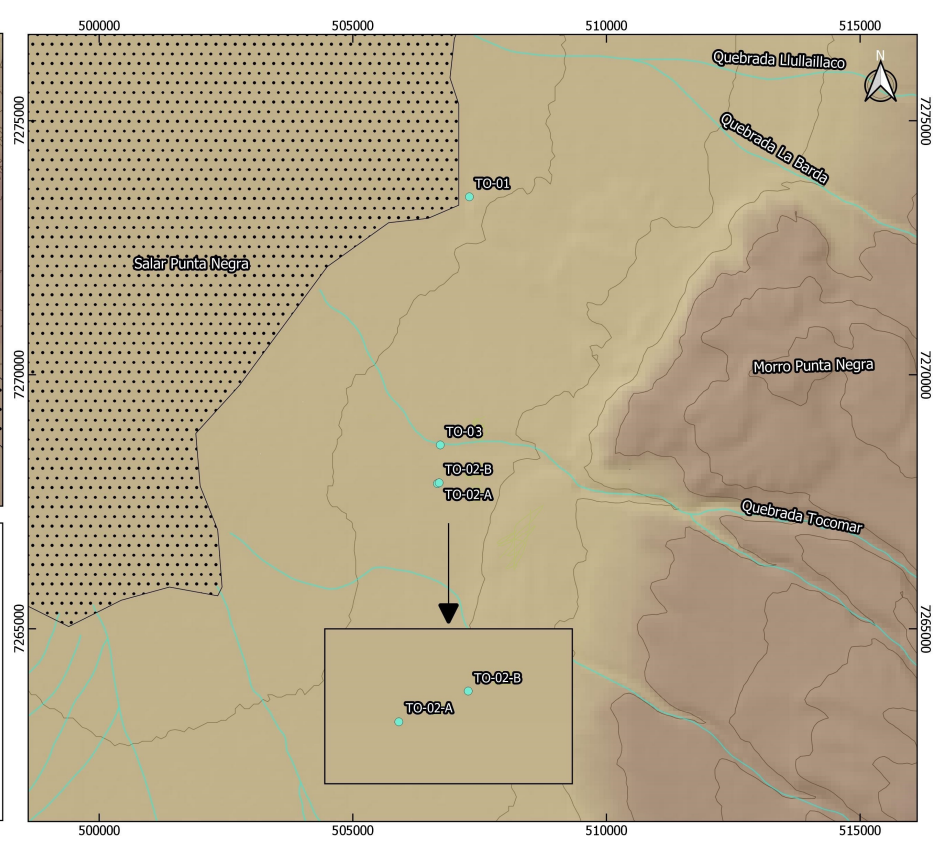


dentro de los cuales destacan las saywas (TO-02 A y B) y una posible instalación inkaica en Tocomar (TO03), que describimos a continuación.

\section{Solsticio de invierno en las saywas de Tocomar}

El sitio TO-02 se compone de dos saywas (TO-02 A y B), en un sector donde no fue posible identificar el camino en terreno como tampoco desde la imagen satelital. Ambas estructuras están distanciadas entre sí por $46 \mathrm{~m}$ y se encuentran conectadas por una hilera de piedras incrustadas en el suelo (Figura 3). La estructura TO-02-A se emplaza al oeste del conjunto y corresponde a una saywa en mal estado de conservación $\mathrm{y}$ con evidencias de haber sido destruida o huaqueada intencionalmente, por lo que la forma de su planta es indeterminada. No obstante, fue posible identificar que la estructura original se compuso de piedras de mayor tamaño, con un relleno de piedras más pequeñas, técnica que hemos identificado también en otras saywas. TO02-B se ubica hacia el este y, al igual que la anterior, se

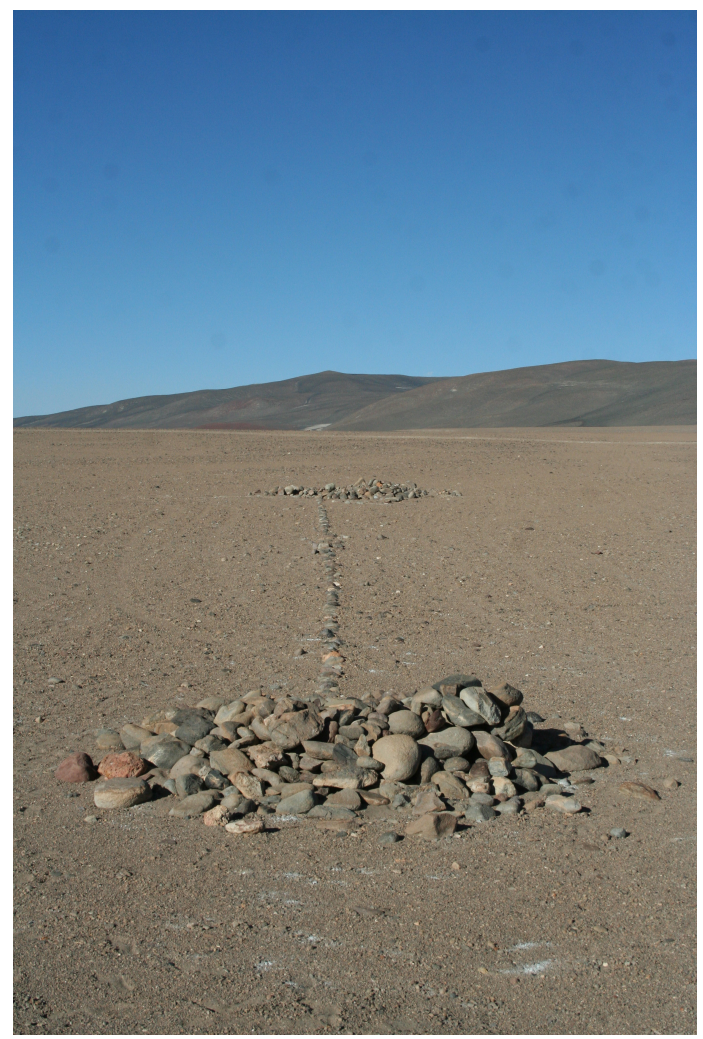

Figura 3. Las saywas destruidas de Tocomar, vista oeste este. Están unidas por una hilera de piedras semi incrustadas en el suelo, que son el punto de referencia para la observación astronómica (foto M. Núñez).

West-east view of the destroyed saywas of Tocomar. The saywas are joined by a line of partly-buried stones, which as a reference point for astronomical observation (photo M. Núñez). encuentra en muy mal estado, por lo que tampoco fue posible identificar su planta. Adicionalmente, ésta se encuentra asociada a un muro con forma de apéndice ubicado en la cara suroeste, probablemente construido con posterioridad a la estructura original. Por otra parte, en la mencionada expedición de 2009 , se encontraron piezas líticas de basalto, semisepultadas bajo las estructuras derruidas del sitio, que corresponden a lo que hemos identificado como un gnomon (sensu Zecenarro 2001) o dispositivo que se colocaba sobre las saywas y que probablemente cumplía la función de servir como referente más preciso de la salida del sol, o para proyectar una sombra sobre la línea que unía ambas columnas. Esta técnica de observación y medición está documentada por cronistas como Sarmiento de Gamboa (1942:93) y Garcilaso de la Vega (1995:120), que mencionan que, entre las columnas astronómicas del Cusco, se trazaba una línea para verificar los movimientos astrales y señalar el punto de salida del sol en fechas relevantes. En este caso, aunque ambos artefactos eran de basalto, destaca el formato y tamaño de la pieza lítica de la columna este, que alcanza $66 \mathrm{~cm}$ alto, y presenta señales de haber sido percutida ${ }^{2}$. El parecido entre esta pieza de basalto con la ilustración de Martín de Murúa (2004 [1615]:105v) que presenta una piedra hincada sobre una torrecilla, nos sugiere que se trata del gnomon o dispositivo que la coronaba (Figura 4) (Sanhueza 2017).

Por otra parte, ese mismo año pudimos constatar que la saywa del lado este había sido prácticamente arrasada recientemente por maquinaria pesada. No obstante, en la década de 1990, Lynch ya señalaba que ambos hitos o mojones habían sido destruidos intencionalmente, atribuyendo eso a la práctica colonial de extirpación de idolatrías, lo que sugiere que a este tipo de estructuras se les reconocía un significado ritual o religioso. De hecho, en ciertos casos, como solía hacerse con los lugares o hitos sagrados, las saywas fueron cristianizadas colocando una cruz sobre ellas (Lynch 1994-95:192). Como veremos más adelante, eso parece haber ocurrido también con las saywas de Vaquillas.

A pesar de la mala conservación que presentan las saywas de Tocomar, fue posible determinar su azimut orientándonos por la línea de piedras que las une. Sin embargo, la medición astronómica inicial no fue del todo concluyente, puesto que no coincidía exactamente con el punto de salida del sol para el solsticio de junio, que en esas latitudes corresponde a $64^{\circ}$ (Cortés y Martín, Informe Astronómico, en Sanhueza 2012).

Esta incongruencia se debía a la diferencia entre el horizonte teórico y el horizonte real del lugar ${ }^{3}$. Esto hacía indispensable observar presencialmente la salida del sol en esa fecha. Fue así como el 21 de junio de 2018 pudimos reconocer, al despuntar el sol, su exacto 


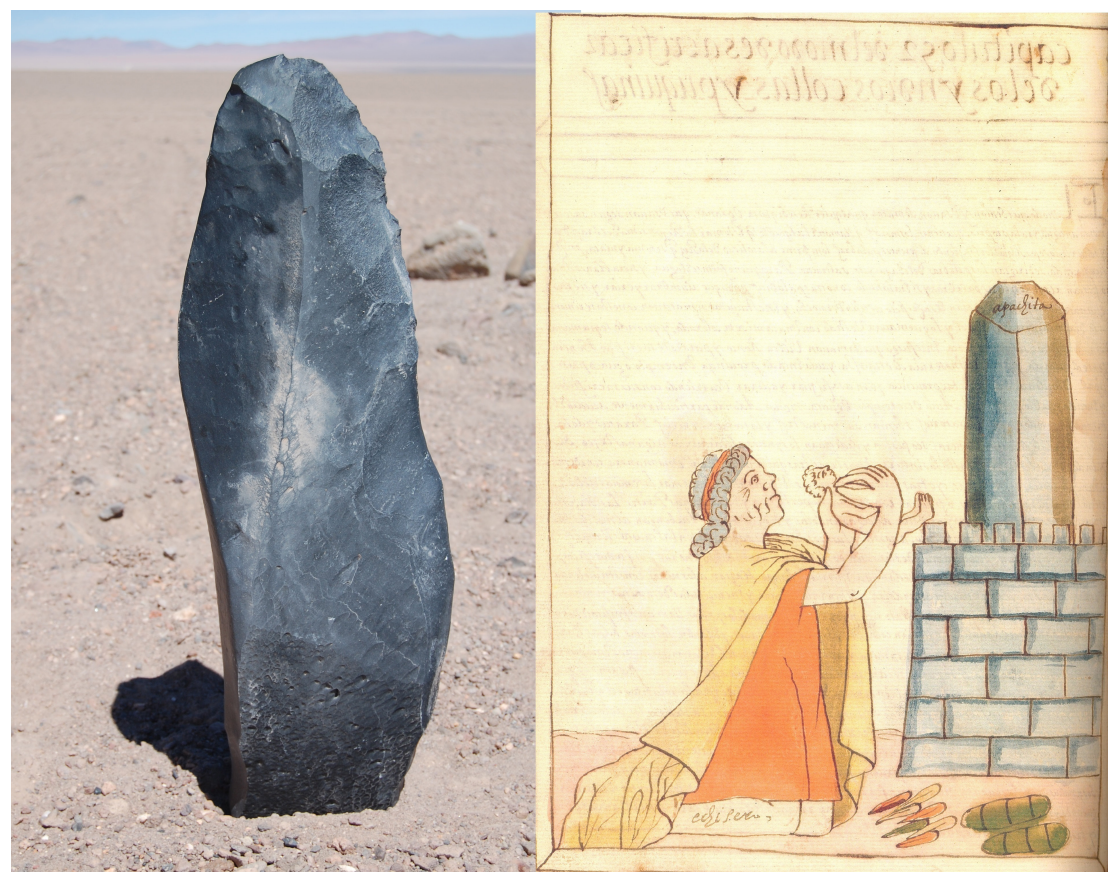

Figura 4. La pieza de basalto encontrada en la saywa este de Tocomar (foto M. Núñez). Se puede apreciar su parecido con la representación de Fray Martín de Murúa (2004 [1615]:105v).

The Basalt piece found in the eastern saywa of Tocomar (photo M. Núñez). Observe the similarity with the representation of Fray Martín de Murúa (2004 [1615]:105v).

alineamiento con las saywas de Tocomar, considerando justamente la presencia de una loma en el horizonte que había alterado el cálculo original en unos pocos grados. Por otra parte, por el hecho de encontrarse totalmente derruidas no era posible establecer un alineamiento totalmente confiable, pero la línea de piedras que unía las saywas desempeñó su función como un referente preciso para la observación del amanecer (Figura 5).

En el Cusco, el solsticio de junio era celebrado con la fiesta de Inti Raymi (Fiesta del Sol), en la que se realizaban muchos "sacrificios". Según Guamán Poma (1992:221), estas ceremonias eran costosas para el Estado, puesto que se realizaban capacochas especialmente con niños, "y enterraua al sacrificio llamado Capac ocha, que enterrauan a los niños ynosentes quinientos y mucho oro y plata y mullo [тиуи]" (Guaman Poma 1992:249). El solsticio corresponde al momento en que el sol llega al punto extremo (al norte o al sur) de su movimiento aparente. A partir de allí comienza a "devolverse" para completar su circuito anual. En estas fechas, según las tradiciones orales inkaicas, el sol se sentaba en su "silla" por dos o tres días, para luego comenzar "a caminar sin descansar" en sentido contrario hacia el otro solsticio (Guaman Poma 1992:830). En la actualidad los habitantes de Atacama señalan que ese día el sol se detiene y descansa en el cielo para luego recomenzar su regreso (Castro y Varela 2004:295). Estos eventos sagrados permitían elaborar el calendario ritual y productivo del año andino y tenían una profunda significación simbólica. Pero ¿por qué se registra la fecha del solsticio de invierno en este sitio del camino inkaico de la cuenca del Salar de Punta Negra?

\section{Asentamiento de Tocomar}

A unos $750 \mathrm{~m}$ al norte de las saywas, al pie de la ladera norte de la Quebrada Tocomar, pudimos identificar el sitio TO-03, correspondiente a un conjunto de cinco recintos habitacionales dispuestos en hilera, cuatro de ellos con muros contiguos. Las construcciones presentan una planta subrectangular, cuyos muros se componen de una hilera de piedras sin relleno y de una cantidad indeterminada de hiladas, dada la mala conservación de las estructuras. En la parte superior de la quebrada se identificaron pequeños apilamientos de piedras asociados a abundante challado de mineral de cobre, correspondiente a malaquita y atacamita, las que parecen haber sido seleccionadas por su alta pureza y reducidas a un tamaño estandarizado (Figueroa et al. 2018) (Figura 6). Aunque no se encontró cerámica asociada al periodo Inka (se identificaron tres fragmentos de la serie preinkaica de San Pedro de Atacama), un hallazgo relevante en este sector el año 2009, correspondió a una pinza inkaica confeccionada en cobre, confirmando que estábamos en la ruta del Inka (Figura 7). 


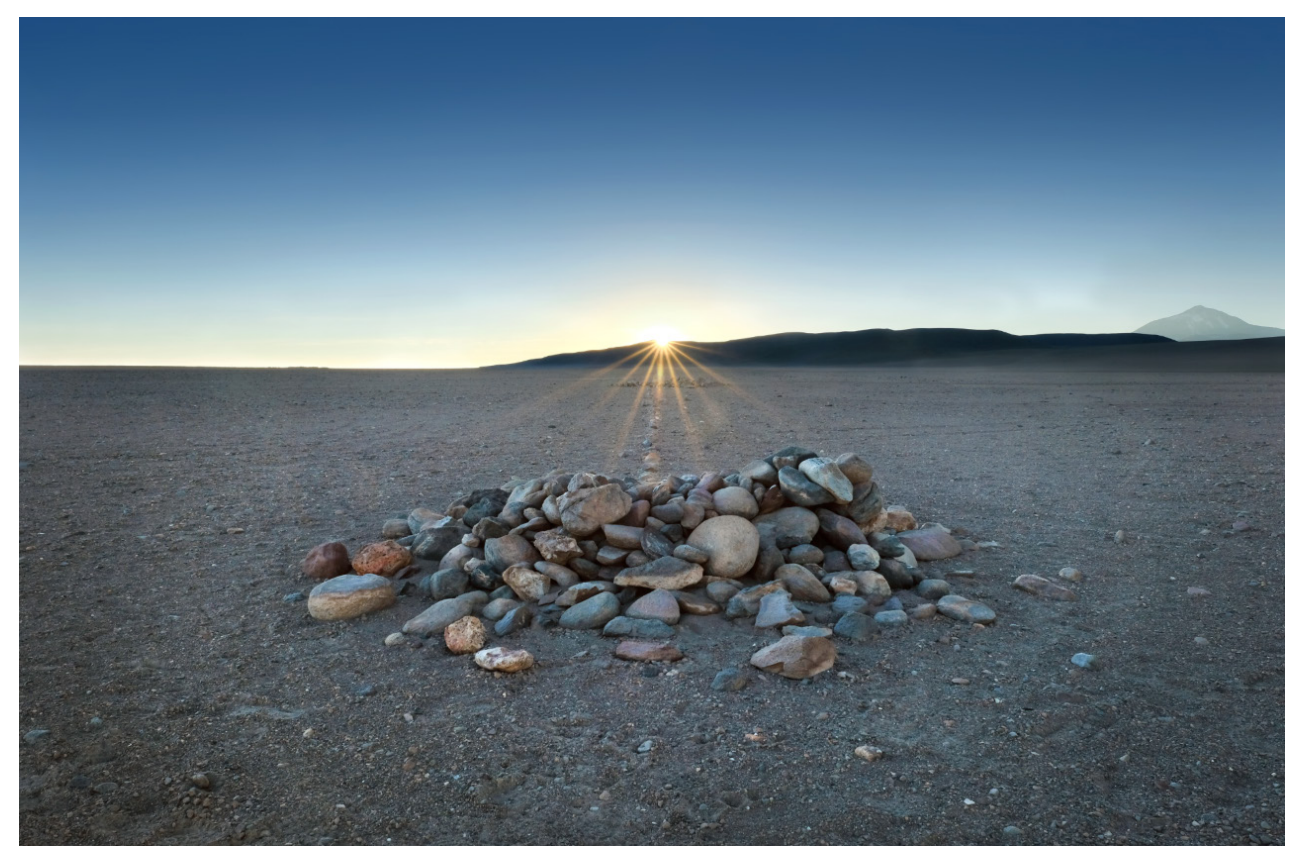

Figura 5. Salida del sol el 21 de junio de 2018 en las saywas de Tocomar. La línea de piedras que las une es el referente principal para la observación del alineamiento (foto R. Bennett).

Sunrise at the saywas of Tocomar on June 21, 2018, winter solstice. The joining line is the main reference for observation of the alignment (photo R. Bennett).

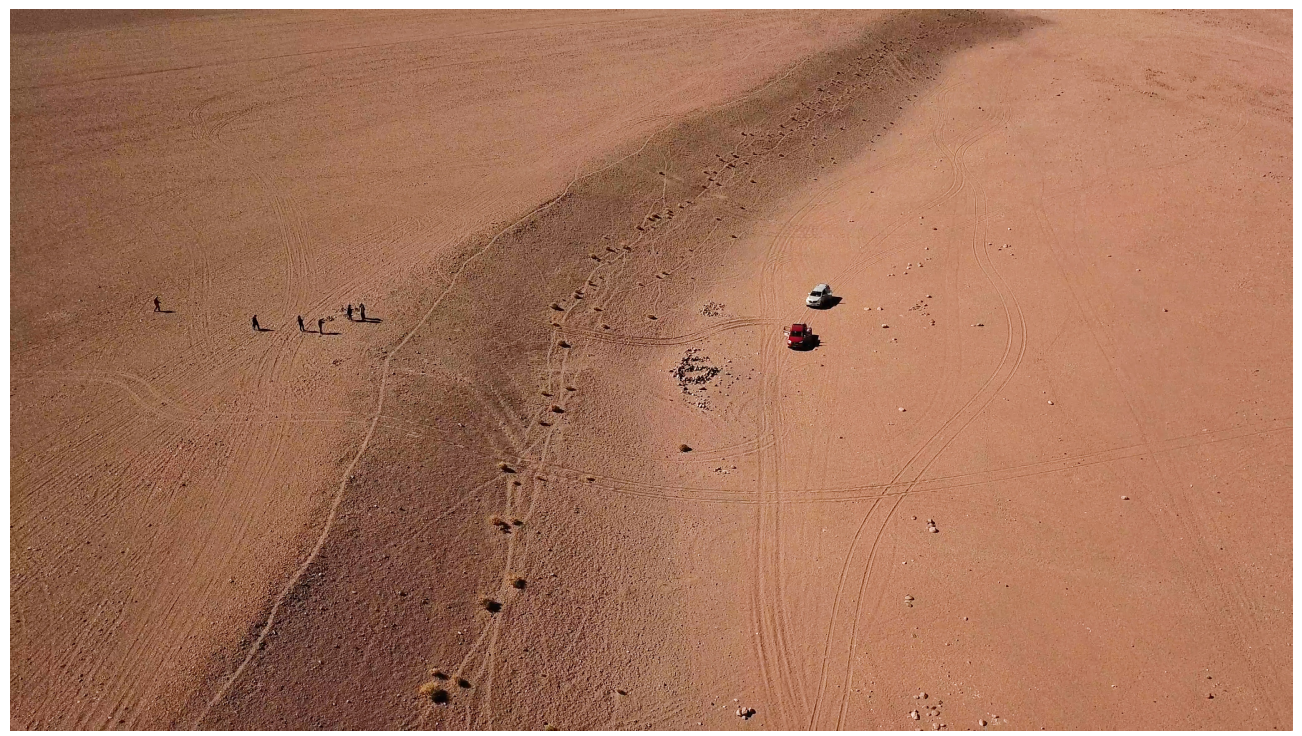

Figura 6. Vista aérea del pequeño asentamiento de Tocomar (TO-03). En el piso de la quebrada se observan los restos de la estructura y en su borde se encuentra el sector de challado ritualmente (foto S. Larraín, gentileza de G. Wernborne).

Aerial view of the tiny settlement of Tocomar (TO-03). The ruins of the structure can be seen on the floor of the ravine and on its edge is the ritually challada area (photo by $S$. Larrain, courtesy of $G$. Wernborne). 


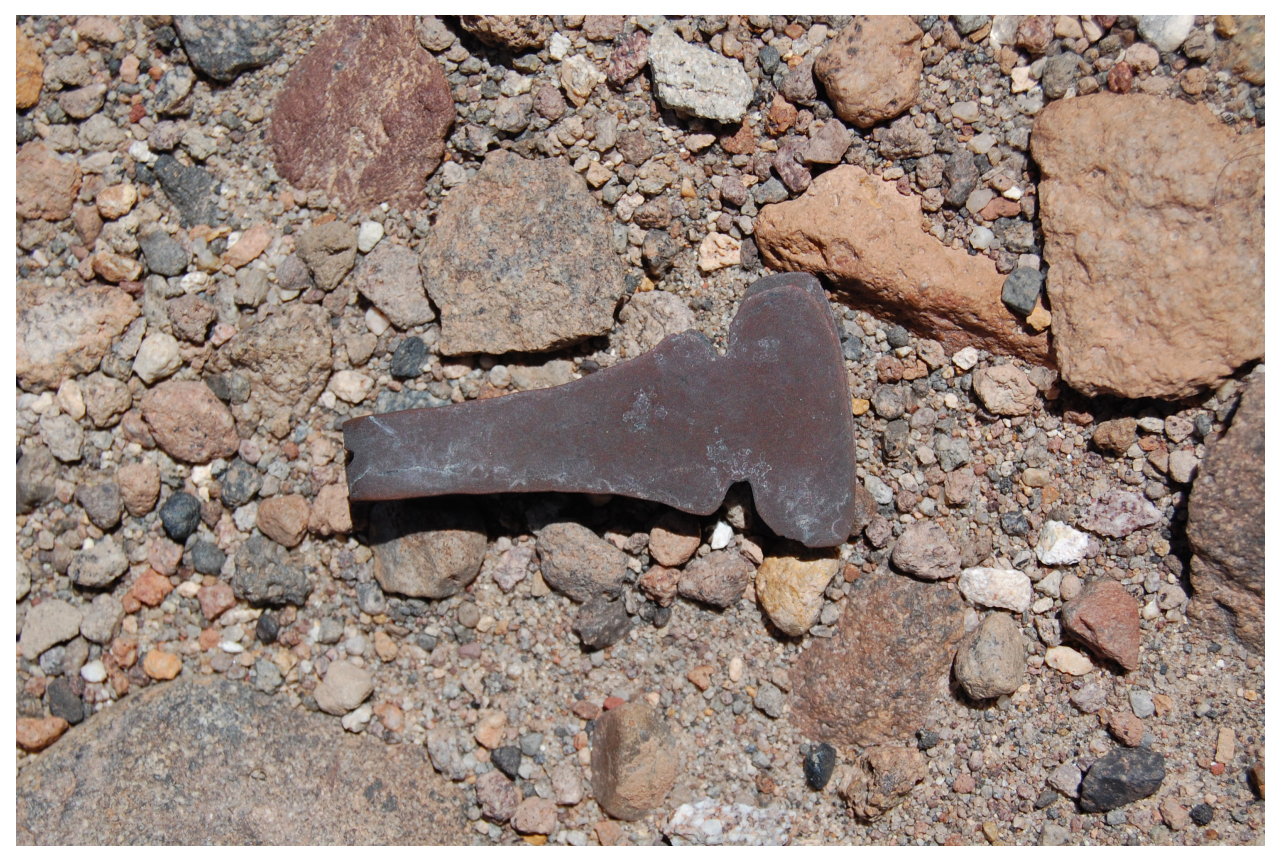

Figura 7. Pinza de cobre inkaica de 3,5 cm de largo, encontrada en las cercanías del asentamiento de Tocomar (foto M. Núñez).

Inka copper clamp $3.5 \mathrm{~cm}$ long, found in the vicinity of the Tambillo of Tocomar (photo M. Núnez).

\section{El Qhapaq Nan entre Tocomar y Río Frío}

Luego de bordear el Salar de Punta Negra, el camino continúa por unos $45 \mathrm{~km}$ en dirección sudoeste hasta alcanzar la gran Quebrada de Río Frío. Aunque el tramo que une Tocomar con esta localidad no ha sido estudiado aún en forma sistemática, se han identificado algunos sitios y puntos relevantes en el interfluvio de las quebradas de Laguna Seca y de Río Frío, que permiten establecer grosso modo su orientación y derrotero. Por una parte, Lynch y Núñez ubicaron, en la ladera oeste de la Quebrada Laguna Seca, un sitio descrito como "tambería" atribuido a periodos anteriores, pero en el cual reconocieron "gran cantidad de alfarería inka y una punta inka de obsidiana" (Lynch y Núñez 1994:158). Como pudimos observar en 2005, en el marco del proyecto Fondecyt 1040290 liderado por el geógrafo Raúl Molina, el sitio está conformado por unas 14 o 15 estructuras, construidas con pirca de lajas sobrepuestas sin mortero. Su formato arquitectónico, como señalan los autores, incluye recintos circulares, subcirculares y otros rectangulares (a excepción de un gran cuarto o plaza) y no respondería a un patrón marcadamente inka, sumado a la presencia de abundante cerámica preinka en su superficie. Sin embargo, aunque no pudimos identificar fragmentos inkaicos, sí los encontramos en un segmento de camino cercano a la quebrada, lo que permite suponer que el asentamiento fue reutilizado en época tardía, como ocurre en otros sitios del Qhapaq Ñan del Desierto de Atacama (Berenguer et al. 2005; Sinclaire 2005). El segmento reconocido del camino tiene una extensión de
$3,2 \mathrm{~km}$ sobre el plano y va a un promedio de $3.600 \mathrm{msm}$ para luego comenzar a descender por una planicie en dirección sur, por el interfluvio entre ambas quebradas. Allí se registraron varios fragmentos cerámicos de una misma vasija de pasta fina y colada, con motivos geométricos y el clásico "helecho", correspondientes a un pequeño aríbalo Inka Imperial (Sinclaire 2005).

\section{Sector Río Frío}

La Quebrada de Río Frío (ca. 3.800-3.500 msm) alberga un estero de rumbo suroeste noreste que se origina en manantiales que brotan en su curso superior y que recoge también las aguas de numerosas quebradas menores de escurrimiento estacional. Ubicada al pie sur de la Sierra El Gólgota, la quebrada es angosta y profunda, con aguas permanentes y de buena calidad, y un fondo bien provisto de vegas. A diferencia de la mayoría de las aguadas de la región, su pequeño caudal nace de la Cordillera de Domeyko y no de la de los Andes. En su curso medio se le unen por la izquierda la Quebrada Vega Cerrada y por la derecha la Quebrada Laguna Seca, y después de un largo trayecto desagua en la orilla sur del Salar de Punta Negra en la cota de 2.970 msm (Figura 8).

\section{Anchallullac. El Río Muy Mentiroso}

La aguada de Río Frío es mencionada frecuentemente por la documentación colonial y posterior. Sin embargo, durante los siglos XVIy XVII se la reconocía con el nombre 


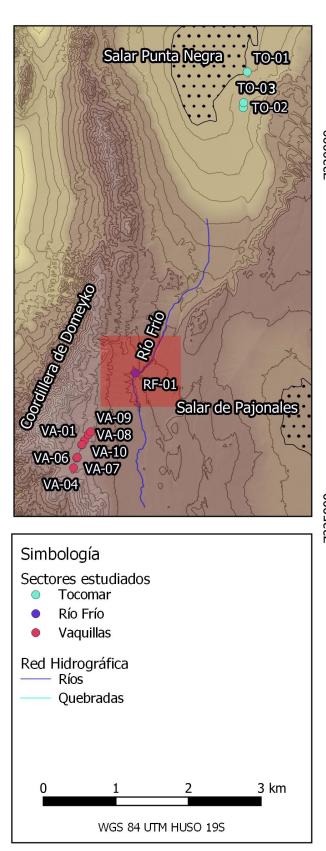

Figura 8. Sector Río Frío.

Río Frío sector.

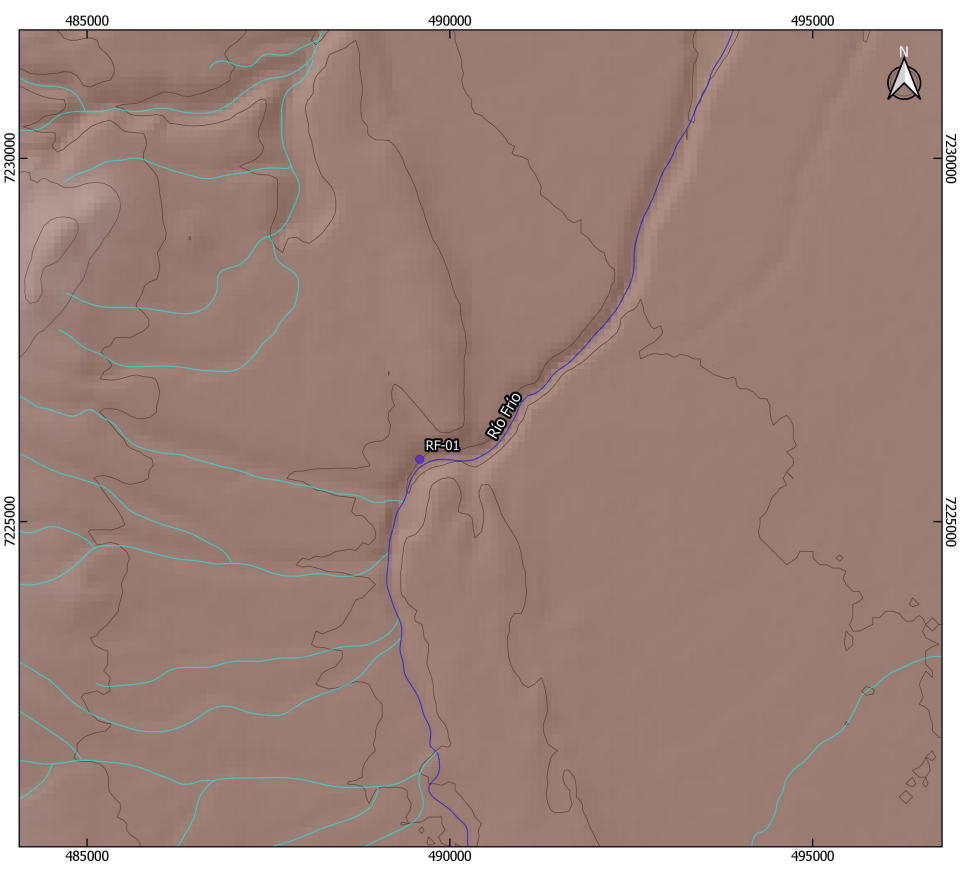

quechua que le otorgaron los inkas: Río Anchallullac o Muy Mentiroso (Vivar 1988:68) ${ }^{4}$. A partir del siglo XVIII, comenzó a ser documentada como Río Frío, figurando como uno de los hitos de agua dulce más importantes de esta zona del Despoblado y de la ruta colonial que unía el Perú con el reino de Chile (Reales Ordenanzas 1778:161162). En el siglo XIX, R. Philippi describe también al Río Frío como una buena fuente de agua y forraje y señala que, al menos desde allí hasta el Portezuelo de Vaquillas, la ruta colonial coincidía con el trazado del antiguo camino del Inka (1860:77).

Es significativa la cantidad de cronistas españoles que mencionan esta localidad como el Río Mentiroso o Anchallullac, en una región como la cuenca del salar de Punta Negra respecto a la cual prácticamente solo se cuenta con información muy general. ¿Por qué este río llamó tanto la atención de los cronistas españoles? De acuerdo a las distintas versiones, se trataba de una aguada cuyo comportamiento era muy particular. El Mentiroso era un río que crecía o decrecía según los movimientos de la luna; que a ciertas horas del día o la noche aumentaba su curso como una peligrosa avenida; o que de improviso se secaba completamente (Sanhueza 2005, 2012). Según Jerónimo de Vivar (1988 [1558]) -quien realmente viajó por el camino del Despoblado- este río dejaba de correr porque se congelaban sus aguas por las bajísimas temperaturas nocturnas que ahí se registran. Sin embargo, el cronista recoge también una tradición oral inkaica sobre los atributos de transformación del
Río Anchallullac. Según su descripción se trataba de "un río chico que corre poca agua, tanta que de un salto se pasara", que "comienza a correr a las nueve de la mañana cuando el sol calienta la nieve que está en una rehoya". Sin embargo, agrega que en algún momento "corre con grande furia y hace mucho ruido a causa del sitio por donde corre". De pronto, al secarse, lo hace "de tal manera y suerte que dicen los indios, que mal lo entienden, que se vuelve el agua arriba a la contra de como ha corrido". Por lo tanto, añade "le llaman los indios Anchallulla, que quiere decir gran [muy] mentiroso" (Vivar 1988 [1558]:68) [énfasis nuestro]. Es decir, según la versión indígena, el río dejaba de correr porque en ciertos momentos cambiaba su curso, devolviéndose en sentido contrario a su corriente.

Otro hecho que destaca la importancia atribuida por los inkas a este río, es que, aunque no pertenece a la cordillera andina, comparte el mismo nombre con la principal wak'a estatal de la región, el Llullaillaco (Reinhard y Ceruti 2000). El nombre de este volcán, que contiene una importante capacocha con ofrendas humanas y con valiosas piezas confeccionadas en alfarería, textiles, oro, plata y mullu, significa en quechua “agua o aguas mentirosas” (González Holguín 1952). Es decir, la toponimia cuzqueña está dando cuenta de una forma de representar un espacio geográfico a través de la elaboración de una cartografía oral expresada también en sus relatos, que abarcaba, definía e interpretaba un espacio simbólico de mayor envergadura. 
Por otra parte, el nombre del río y del volcán nos remite a un periodo específico del calendario andino asociado a las lluvias estivales y a sus posibles consecuencias. El año andino en la región del Cusco como también en Atacama (actualmente, región de Antofagasta), se organizaba principalmente en torno a dos ciclos opuestos, la estación de lluvias y la estación seca. La primera, que abarcaba entre diciembre y marzo correspondía a la época más lluviosa del año, mientras que de abril a julio imperaba con más fuerza el tiempo seco y frío, para luego tener escasos episodios de lluvias entre agosto y noviembre. Si bien el tiempo de lluvias aseguraba la renovación de los ciclos naturales, muchas veces las inundaciones, diluvios y desbordes de ríos, provocaban grandes estragos. Por eso, al referirse al mes de "marzo" como culminación de las lluvias, Guaman Poma (1992 [1614]:1034) advierte que en este tiempo los ríos podían ser engañosos y peligrosos. De hecho, un río peligroso era llamado llullak mayu, río "mentiroso" o "engañador" (González Holguín 1952:662). Esta categoría cultural de "río peligroso" como un "río mentiroso" aún está en uso, de acuerdo a una publicación de la Dirección Regional de Comercio Exterior y Turismo Amazonas (DIRCETUR) de Perú, del año 2012. Allí se señala que un río de la zona, al que se denomina como "Llulla Yacu", "Río mentiroso" y "Agua mentirosa", había reaparecido después de varios años, y amenazaba con inundar con su caudal al poblado de Leymebamba, en el Departamento de Amazonas 5 . Por otra parte, según un estudio sobre toponimia y geografía cultural del Mato Grosso, el término niwitakadi (o naitaca), de origen kadiwéu refiere también a un río temporal, que desaparece en la estación seca, pero puede volver a aparecer, por lo que se lo conoce como "río mentiroso" o "lugar de la mentira" (De Souza 2008:61). De manera que, podemos concluir que los "ríos mentirosos" corresponden a una categoría de ríos que se registran en ambientes ecológicos andinos e incluso de selva. Ríos que pueden llegar a ser muy destructivos, que engañan, que aparecen y desaparecen y que se asocian con la estación de lluvias del calendario andino. Pero nuevamente surge la pregunta ¿qué hace un "río mentiroso" (Ancha Llullac o Llulla Yacu) en pleno corazón del Despoblado de Atacama y en una de las regiones más áridas del planeta?

\section{Tambo de Río Frío}

Desde el punto de vista arqueológico existen controversias respecto a la ocupación inka en Río Frío. Niemeyer y Rivera (1983:123-125, 149, 178; figs. 9-11, 22) reportan como Tambo de Río Frío un recinto de piedra y una bodega excavada en la barranca, con fragmentos cerámicos mayoritariamente de la serie preinkaica de San Pedro de Atacama (salvo un borde de escudilla playa posiblemente inka). Como se ha dicho, Lynch y Núñez (1994:158), sostienen que el verdadero "tambo" se ubicaría en una pequeña colina que separa Río Frío de la Quebrada Laguna Seca (Sinclaire 2006). En nuestro caso, registramos el denominado Tambo de Río Frio (RF- 01) mencionado por Niemeyer y Rivera $(1983: 124)$ y un posible segmento no publicado del camino inka.

El sitio RF-01 corresponde a un asentamiento compuesto por cuatro estructuras de distinta morfología y emplazado a media ladera de cerro (Figura 9). La principal (E1) es de planta rectangular de $3 \mathrm{~m} \mathrm{x}$ $2 \mathrm{~m}$, y está compuesta de muros de doble hilera con relleno. El eje de la estructura es de orientación cardinal este-oeste y está definida por un vano de acceso tipo peldaño, ubicado en el muro este. El material cultural identificado incluye cinco fragmentos cerámicos, al parecer preinkaicos, además de restos malacológicos, óseos, mineral de cobre, vidrio, latas y herraduras de mula (Figura 9). Hacia el sector norte del sitio, se identificó lo que parece ser un segmento del Qhapaq Ñan que conectaba el fondo de la quebrada con la planicie ubicada sobre ésta, en dirección a Vaquillas. El camino presenta una visibilidad nítida con un ancho de hasta $3 \mathrm{~m}$, y fue construido excavando el talud de la ladera y despejando las piedras (Figura 10).

\section{El tramo de Río Frío al portezuelo de Vaquillas}

Hacia el sur de Río Frío, el camino continúa por una amplia meseta desde la cual se divisa al fondo la Sierra de Vaquillas perteneciente a la Cordillera de Domeyko, que va orientándose hacia el este, hasta alcanzar la cadena de los Andes. La extensa planicie inclinada que se inicia en este segmento del camino, denominada Llanos de Vaquilla Alta por Niemeyer y Rivera (1983), va ascendiendo hasta el portezuelo y ofrece muy buena visibilidad en todas direcciones: al noreste el Llullaillaco (6.739 msm), acompañado de los cerros Aguas Calientes $(5.070 \mathrm{~m})$, de la Pena (5.260 m) y Volcán Azufre o Lastarria (5.697 m); al sur, se observa la Serranía de Vaquillas y el portezuelo, al que se accede atravesando un extenso pedregal. El camino inka discurre con un trazado recto que registra las alturas promedio más elevadas de la ruta desde Peine (ca. $4.000 \mathrm{msm}$ ), como también las condiciones más duras para la travesía ya que está expuesto a los fuertes y fríos vientos que soplan durante el día, y a las gélidas temperaturas de la noche (Figura 11). No obstante, es uno de los trechos con mayor densidad de restos arqueológicos, y cuenta con una notable cantidad y variedad de pequeñas estructuras posiblemente asociadas a actividades de caza, pastoreo, minería y tráfico caravanero (Niemeyer y Rivera 1983; Tabla 1). Efectivamente, en los poco más de $20 \mathrm{~km}$ 


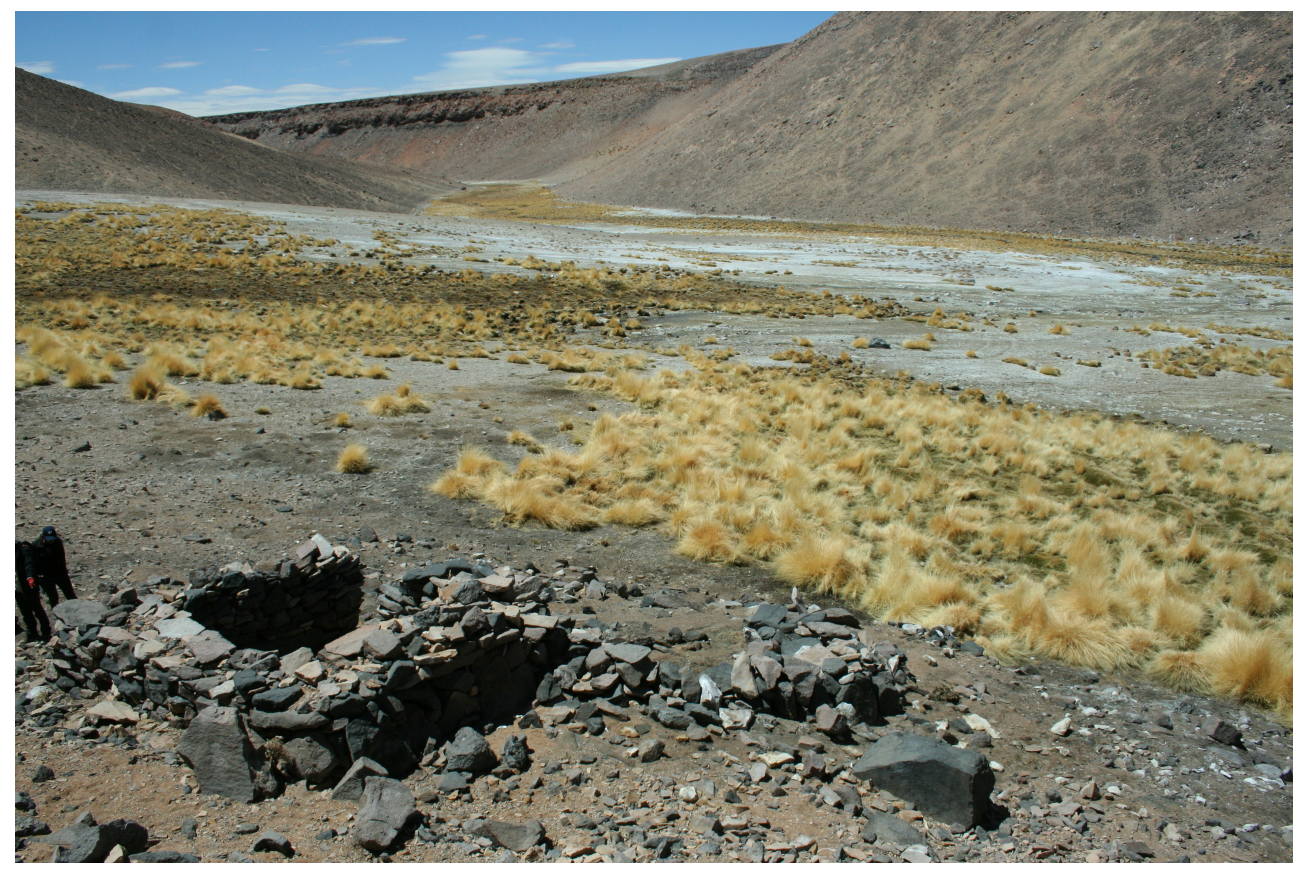

Figura 9. El llamado Tambo (RF-01) y la vega de Río Frío (foto C. Mercado). The so-called Tambo (RF-01) and pastures of Río Frío (photo C. Mercado).

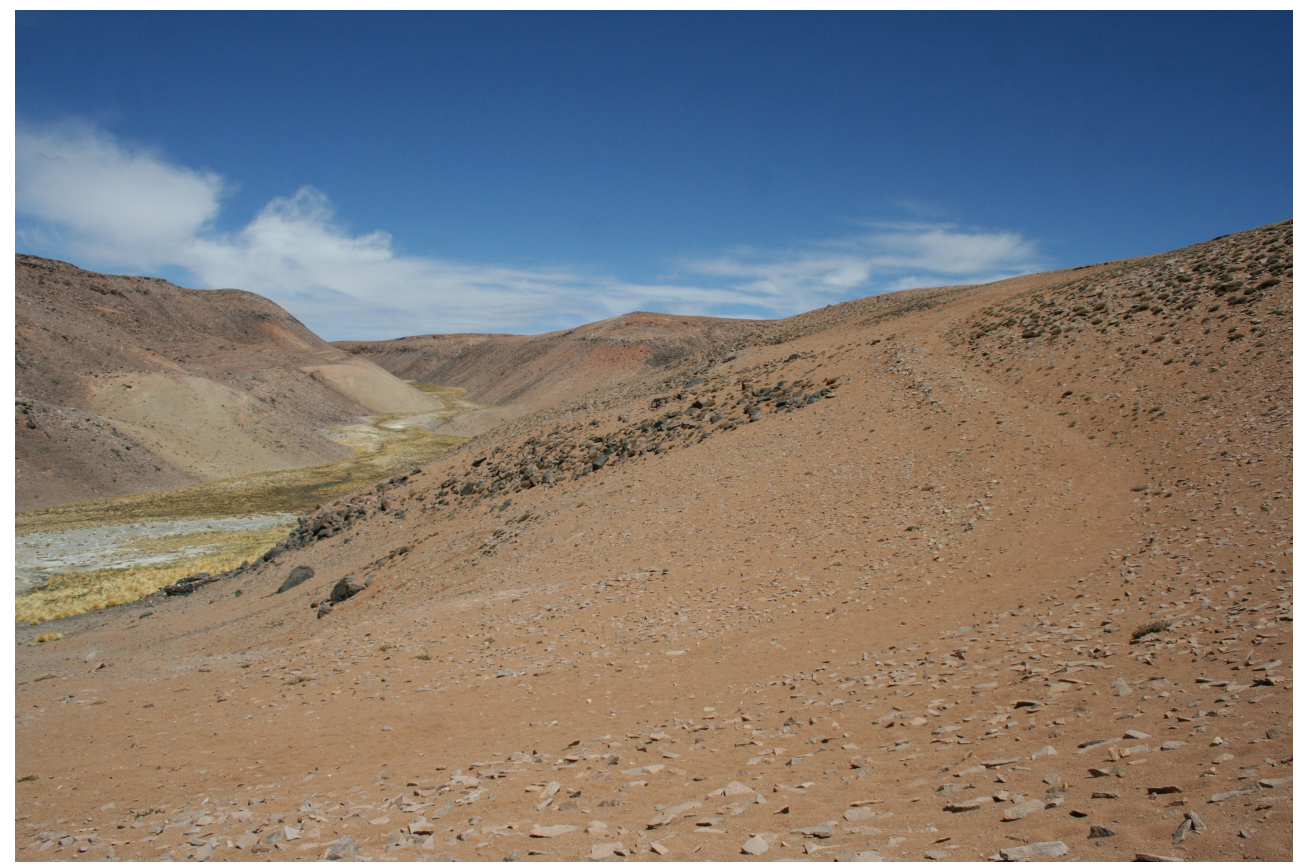

Figura 10. Segmento de camino que une el Tambo de Río Frío con los altos de la quebrada homónima (foto C. Mercado). Section of the path that links the Tambo of Río Frío with the higher area of the Río Frío ravine (photo C. Mercado). 

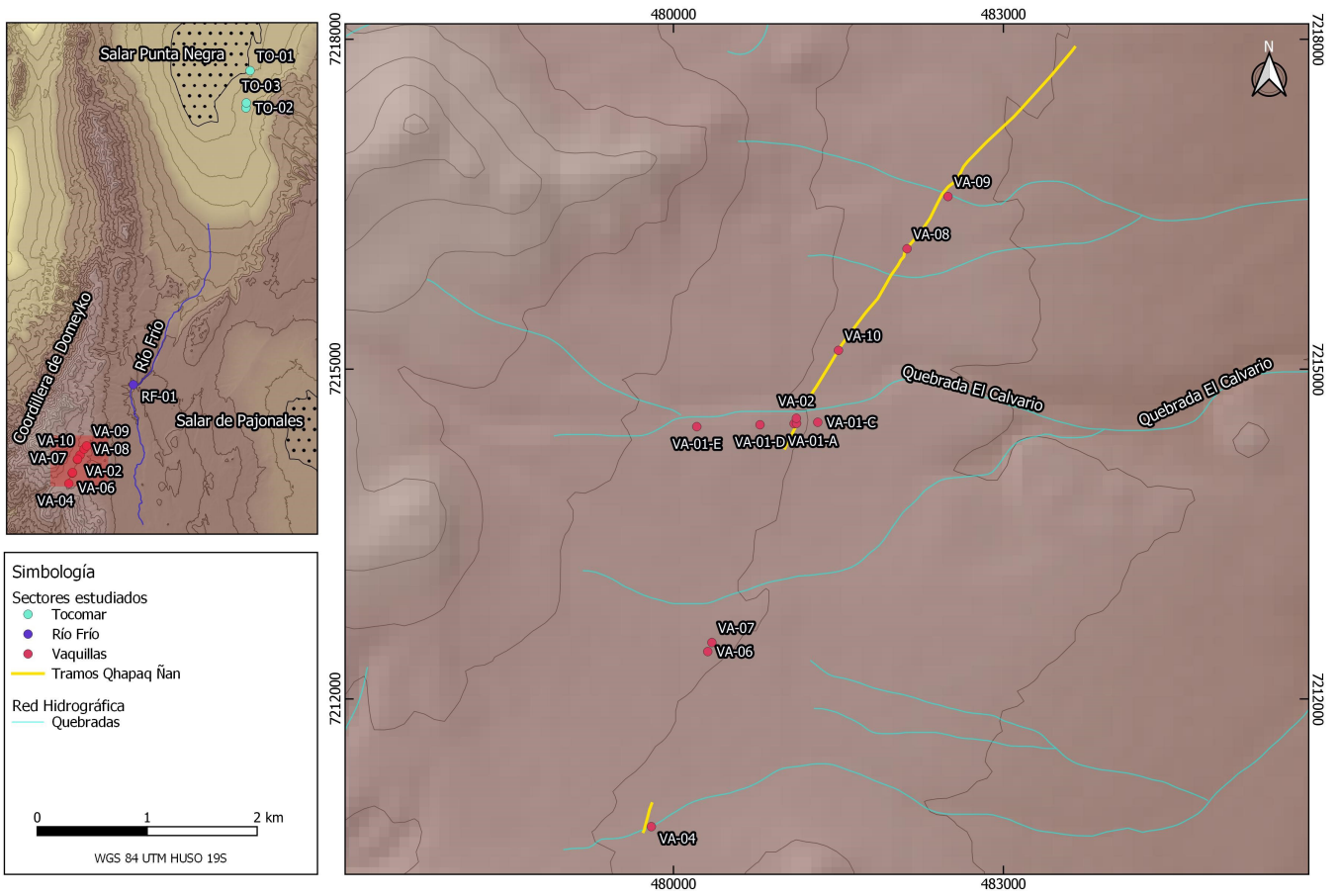

Figura 11. Sector Vaquillas.

Vaquillas sector.

que distan entre la cabecera de Río Frío y el Portezuelo de Vaquillas, Niemeyer y Rivera (1983; véase también Núñez 1981:57), reportan 52 estructuras menores distribuidas en 34 conjuntos, tales como recintos en media luna, recintos circulares, muretes rectos, estructuras en coma, recintos en $\mathrm{U}$, entre otros ${ }^{7}$.

En nuestro caso, en el sector El Pedregal, registramos distintos conjuntos de refugios temporales, pero distinguimos específicamente tres sitios (VA-09, VA-08 y VA-10) asociados al camino inka, y desde los cuales éste era visible a escasos metros (Tabla 1).

El siguiente hito relevante, corresponde a la quebrada y paskana del Calvario que baja de la Cordillera de Domeyko hacia el este, y en cuyo borde sur se encuentran las saywas de Vaquillas. Esta quebrada cuenta con una aguada permanente, que no había sido documentada hasta el momento, ubicada a unos $750 \mathrm{~m}$ al oeste del punto por donde cruza el Qhapaq Ñan. En su zona más ancha la aguada alcanza unos $58 \mathrm{~m}$, y se extiende por aproximadamente $300 \mathrm{~m}$ de largo. La llamamos paskana porque así la denomina la documentación histórica, y porque define un espacio provisto de recursos naturales (refugio, agua, leña y forraje) para el descanso y reaprovisionamiento en la ruta. Por sus características estos lugares están rodeados o tienen en sus cercanías sitios o estructuras arqueológicas de mayor o menor complejidad (Figura 12) . $^{8}$.
En ese contexto hay que comprender el sitio o asentamiento VA-02, ubicado a media ladera de la Quebrada El Calvario y a $40 \mathrm{~m}$ al norte de las saywas centrales de Vaquillas. Este conjunto se compone de al menos 10 estructuras de diversa morfología, como plantas circulares, elipsoidales, subtriangulares y estructuras en coma (Tabla 1). Se trata de pequeños refugios, abiertos hacia el noreste (mirando al Volcán Llullaillaco), y dando la espalda a la quebrada para guarecerse del viento. Una inspección visual realizada a estas estructuras y sus alrededores en 2004, permitió identificar una significativa variedad y cantidad de material cultural. La alfarería correspondía a fragmentos del periodo Intermedio Tardío y Tardío del Salar de Atacama y del Río Loa, como también del Valle de Copiapó. Se identificaron además fragmentos decorados de cerámica Diaguita Inka, Inka Local e Inka Cuzqueña, y cerámica de tipo colonial (con mica) y etnográfica tardía. A ello se agrega la presencia de mineral de cobre molido (malaquita, atacamita o turquesa), muy probablemente arrojado allí como ofrenda (Sinclaire 2005). La cerámica diagnóstica, como también el challado de mineral, expresan la importancia de esta ruta y de esta paskana en particular, y dan testimonio no solo del valor estratégico del sitio, sino también de la carga simbólica y ritual que le otorgaron quienes atravesaban el Despoblado antes, durante y después del Inka. 
Tabla 1. Hallazgos arqueológicos en los sectores Tocomar, Río Frío y Vaquillas. El orden de los números del código de hallazgos no refleja su secuencia en el eje norte-sur, sino solo la secuencia de la prospección.

Archaeological finds in the Tocomar, Río Frío and Vaquillas sectors. The order of the code numbers does not reflect their sequence on the north-south axis, but rather the sequence of the survey.

\begin{tabular}{|c|c|c|c|c|c|c|}
\hline Sector & Hallazgo & Ubicación & Código & Descripción & Materiales & Camino inka \\
\hline Tocomar & $\begin{array}{l}\text { Refugio de } \\
\text { Morro Punta } \\
\text { Negra }\end{array}$ & $\begin{array}{l}\text { Emplazado a } \\
\text { media ladera } \\
\text { del morro, con } \\
\text { visibilidad hacia } \\
\text { el salar de Punta } \\
\text { Negra. }\end{array}$ & TO-01 & $\begin{array}{l}\text { El sitio se compone de una } \\
\text { sola estructura de planta } \\
\text { irregular. }\end{array}$ & $\begin{array}{l}\text { Se registran } \\
\text { fragmentos cerámicos } \\
\text { indeterminados, restos } \\
\text { óseos de animales y varios } \\
\text { percutores de basalto y } \\
\text { lascas. }\end{array}$ & $\begin{array}{l}\text { No se constató asociación } \\
\text { con el camino inka. }\end{array}$ \\
\hline Tocomar & $\begin{array}{l}\text { Saywas de } \\
\text { Tocomar } \\
\text { (Lynch } \\
\text { 1994). }\end{array}$ & $\begin{array}{l}\text { Emplazado } \\
\text { en explanada } \\
\text { pedregosa con } \\
\text { visibilidad hacia } \\
\text { el salar de Punta } \\
\text { Negra. }\end{array}$ & TO-02 & $\begin{array}{l}\text { Compuesto por dos } \\
\text { estructuras (TO-02 A y B) } \\
\text { distanciadas entre sí por } \\
46 \mathrm{~m} \text {, que se encuentran } \\
\text { conectadas por una hilera } \\
\text { de piedras naturales } \\
\text { redondeadas (Figura 3). } \\
\text { La estructura TO-02-A } \\
\text { se emplaza al oeste del } \\
\text { conjunto y corresponde a un } \\
\text { apilamiento de piedras con } \\
\text { mal estado de conservación } \\
\text { y con evidencias de haber } \\
\text { sido huaqueada. La saywa } \\
\text { TO-02-B se ubica hacia } \\
\text { el este y, al igual que la } \\
\text { estructura anterior, se } \\
\text { encuentra en mal estado de } \\
\text { conservación, presentando } \\
\text { una huella de remoción de } \\
\text { sedimento posiblemente } \\
\text { ejecutada por una } \\
\text { maquinaria pesada. }\end{array}$ & $\begin{array}{l}\text { En expedición nuestra } \\
\text { de } 2009 \text { se encontraron } \\
\text { sendas piezas líticas de } \\
\text { basalto, semi sepultadas, } \\
\text { que corresponden a lo } \\
\text { que hemos identificado } \\
\text { como un gnomon } \\
\text { o dispositivo que } \\
\text { se colocaba sobre } \\
\text { las saywas y que } \\
\text { probablemente cumplían } \\
\text { la función de facilitar una } \\
\text { lectura más precisa, o de } \\
\text { proyectar una sombra } \\
\text { sobre la línea que unía } \\
\text { ambas columnas. }\end{array}$ & $\begin{array}{l}\text { No se constató asociación } \\
\text { con el camino inka. }\end{array}$ \\
\hline Tocomar & $\begin{array}{l}\text { Asentamiento } \\
\text { de Q. de } \\
\text { Tocomar }\end{array}$ & $\begin{array}{l}\text { Pie de la ladera } \\
\mathrm{N} \text { de la quebrada } \\
\text { Tocomar }\end{array}$ & TO-03 & $\begin{array}{l}\text { Asentamiento de cinco } \\
\text { recintos habitacionales } \\
\text { de planta subrectangular } \\
\text { dispuestos en hilera (Figura 6). }\end{array}$ & $\begin{array}{l}\text { En la ceja de la quebrada } \\
\text { hay apilamientos de } \\
\text { piedras con abundante } \\
\text { challado de mineral } \\
\text { de cobre (malaquita y } \\
\text { atacamita) reducidos a } \\
\text { un tamaño estandarizado } \\
\text { de más o menos } 2 \mathrm{~cm} \\
\text { (Figueroa et al. } 2018 \text { ) } \\
\text { (Figura 6). Se contabilizan } \\
\text { tres fragmentos cerámicos } \\
\text { de la serie preinkaica de } \\
\text { San Pedro de Atacama. } \\
\text { En 2009 se encontró } \\
\text { en superficie una pinza } \\
\text { inka confeccionada en } \\
\text { cobre (Figura 7). Posible } \\
\text { instalación inkaica. }\end{array}$ & $\begin{array}{l}\text { No se constató } \\
\text { asociación con el } \\
\text { camino inka. }\end{array}$ \\
\hline Río Frío & $\begin{array}{l}\text { Tambo de } \\
\text { Río Frío } \\
\text { (Lynch y } \\
\text { Núñez 1994; } \\
\text { Niemeyer y } \\
\text { Rivera 1983; } \\
\text { Sinclaire } \\
\text { 2006). }\end{array}$ & $\begin{array}{l}\text { Emplazado } \\
\text { en el fondo } \\
\text { de quebrada } \\
\text { asociada } \\
\text { directamente a } \\
\text { Río Frío. }\end{array}$ & RF-01 & $\begin{array}{l}\text { Asentamiento compuesto por } \\
\text { cuatro estructuras de distinta } \\
\text { morfología. Se identificó una } \\
\text { estructura de planta rectangular } \\
\text { y muros de doble hilera con } \\
\text { relleno (Figura 9). }\end{array}$ & $\begin{array}{l}\text { Se registran cinco } \\
\text { fragmentos cerámicos, } \\
\text { que incluyen un } \\
\text { cuello de vasija color } \\
\text { anaranjado, un borde } \\
\text { en coma con engobe } \\
\text { blanco y pasta fina, y un } \\
\text { asa-borde de superficie } \\
\text { café alisada. También } \\
\text { se cuentan fragmentos } \\
\text { malacológicos, mineral } \\
\text { de cobre, y materiales } \\
\text { subactuales. }\end{array}$ & $\begin{array}{l}\text { Hacia el sector N del } \\
\text { asentamiento se identificó } \\
\text { un segmento del Qhapaq } \\
\text { Ñan, que conecta el piso } \\
\text { de la quebrada con la } \\
\text { planicie ubicada sobre } \\
\text { ésta, en dirección hacia los } \\
\text { Llanos de Vaquilla Alta. El } \\
\text { camino presenta hasta } 3 \text { m } \\
\text { de ancho (Figura 10). }\end{array}$ \\
\hline
\end{tabular}


Continuación Tabla 1.

\begin{tabular}{|c|c|c|c|c|c|c|}
\hline Sector & Hallazgo & Ubicación & Código & Descripción & Materiales & Camino inka \\
\hline Vaquillas & $\begin{array}{l}\text { Saywas de } \\
\text { Vaquillas } \\
\text { (Geda 1995; } \\
\text { Niemeyer y } \\
\text { Rivera 1983; } \\
\text { Núñez 1981). }\end{array}$ & $\begin{array}{l}\text { Emplazado } \\
\text { en la planicie, } \\
\text { inmediatamente } \\
\text { al S de la } \\
\text { quebrada El } \\
\text { Calvario. }\end{array}$ & VA-01 & $\begin{array}{l}\text { Conjunto que presenta } \\
\text { dos saywas (VA-01 A y } \\
\text { B), además de otros dos } \\
\text { apilamientos (VA-01 C y } \\
\text { D) ubicados al E y W de las } \\
\text { dos saywas centrales. Las } \\
\text { saywas VA-01 A y B distan } \\
\text { entre sí } 21,7 \text { m. La estructura } \\
\text { VA-01-A se emplaza hacia } \\
\text { el W del camino inka y } \\
\text { corresponde a un apilamiento } \\
\text { de piedras de sección } \\
\text { cuadrangular que se halla en } \\
\text { mal estado de conservación. } \\
\text { La saywa VA-01-B se } \\
\text { emplaza hacia el E del } \\
\text { camino inka, y corresponde a } \\
\text { un apilamiento de piedras con } \\
\text { forma de planta subcircular. } \\
\text { Estas saywas se encuentran } \\
\text { asociadas a dos apilamientos } \\
\text { de piedras de los cuales no se } \\
\text { ha corroborado su orientación } \\
\text { astronómica (VA-01 C y } \\
\text { D). El apilamiento VA-01-C } \\
\text { se encuentra emplazado a } \\
\text { 194 m al E de la estructura } \\
\text { VA-01-B, mientras que } \\
\text { el apilamiento VA-01-D } \\
\text { se encuentra emplazado a } \\
312 \text { m al W de la estructura } \\
\text { VA-01-A. }\end{array}$ & $\begin{array}{l}\text { No se identificó mate- } \\
\text { rial cultural. }\end{array}$ & $\begin{array}{l}\text { Asociado a este sector se } \\
\text { reconoció un segmento } \\
\text { de camino inka de baja } \\
\text { visibilidad. }\end{array}$ \\
\hline Vaquillas & $\begin{array}{l}\text { Asenta- } \\
\text { miento El } \\
\text { Calvario }\end{array}$ & $\begin{array}{l}\text { Conjunto } \\
\text { emplazado a } \\
\text { media ladera } \\
\text { del flanco S de } \\
\text { la quebrada El } \\
\text { Calvario. }\end{array}$ & VA-02 & $\begin{array}{l}\text { Se compone de } 10 \text { estructuras } \\
\text { de diversas morfologías, } \\
\text { dentro de las que se incluyen } \\
\text { recintos de planta circular, } \\
\text { elipsoidal, subtriangular y } \\
\text { estructuras "en coma". }\end{array}$ & $\begin{array}{l}\text { No se identificó mate- } \\
\text { rial cultural. }\end{array}$ & $\begin{array}{l}\text { No se constató asociación } \\
\text { con el camino inka. }\end{array}$ \\
\hline Vaquillas & $\begin{array}{l}\text { Llanos de } \\
\text { Vaquilla Alta } \\
\text { (Niemeyer y } \\
\text { Rivera 1983). }\end{array}$ & $\begin{array}{l}\text { Emplazados en } \\
\text { una llanura al S } \\
\text { de la quebrada } \\
\text { El Calvario. }\end{array}$ & VA-04 & $\begin{array}{l}\text { Conjunto de estructuras } \\
\text { menores dentro de las que se } \\
\text { encuentran hitos, parapetos o } \\
\text { paravientos, refugios en "L", } \\
\text { en "U", circulares, elípticos, } \\
\text { "en coma" y abovedados en } \\
\text { barrancas. } \\
\text { Compuesto por } \\
\text { estructuras de muros } \\
\text { simples y parapetos en } \\
\text { forma de "L". } \\
\text { Corresponde a un } \\
\text { asentamiento compuesto por } \\
\text { cinco estructuras. }\end{array}$ & $\begin{array}{l}\text { Registro de cerámica } \\
\text { Diaguita Inka. Se } \\
\text { reconocieron fragmentos } \\
\text { de un aríbalo con engobe } \\
\text { blanco y pintura negra } \\
\text { sobre blanco, y negro } \\
\text { sobre rojo (reticulado). }\end{array}$ & $\begin{array}{l}\text { No se constató } \\
\text { asociación con el } \\
\text { camino inka. }\end{array}$ \\
\hline \multirow[t]{2}{*}{ Vaquillas } & \multirow[t]{2}{*}{$\begin{array}{l}\text { El Pedregal } \\
\text { (Niemeyer } \\
\text { y Rivera } \\
\text { 1983). }\end{array}$} & \multirow[t]{2}{*}{$\begin{array}{l}\text { Emplazados } \\
\text { en una llanura } \\
\text { pedregosa al N } \\
\text { de la quebrada } \\
\text { de El Calvario. }\end{array}$} & VA-09 & $\begin{array}{l}\text { Compuesto por un parapeto } \\
\text { en forma de "coma", } \\
\text { similar a la factura de los } \\
\text { asentamientos VA-06 y } \\
\text { VA- } 07 \text {. } \\
\text { Corresponde a un asenta- } \\
\text { miento compuesto de ocho } \\
\text { estructuras que incluyen } \\
\text { parapetos en forma de arco, } \\
\text { estructuras elipsoidales, } \\
\text { paravientos en forma de "U" } \\
\text { y"E". }\end{array}$ & $\begin{array}{l}\text { Registro de cerámica } \\
\text { inka local. }\end{array}$ & $\begin{array}{l}\text { Se reconoció un seg- } \\
\text { mento del camino inka } \\
\text { ubicado a } 7,5 \mathrm{~m} \text { de la } \\
\text { estructura (rumbo de } \\
12^{\circ} \text { ). }\end{array}$ \\
\hline & & & VA-10 & $\begin{array}{l}\text { Corresponde a una estruc- } \\
\text { tura abierta de muro sim- } \\
\text { ple y con forma de "U". }\end{array}$ & $\begin{array}{l}\text { No se registró material } \\
\text { cultural. }\end{array}$ & $\begin{array}{l}\text { Esta estructura se } \\
\text { asocia a un segmento } \\
\text { de camino de } 2,4 \mathrm{~m} \\
\text { de ancho (rumbo } 40^{\circ} \\
\text { a } 70^{\circ} \text { ). }\end{array}$ \\
\hline
\end{tabular}




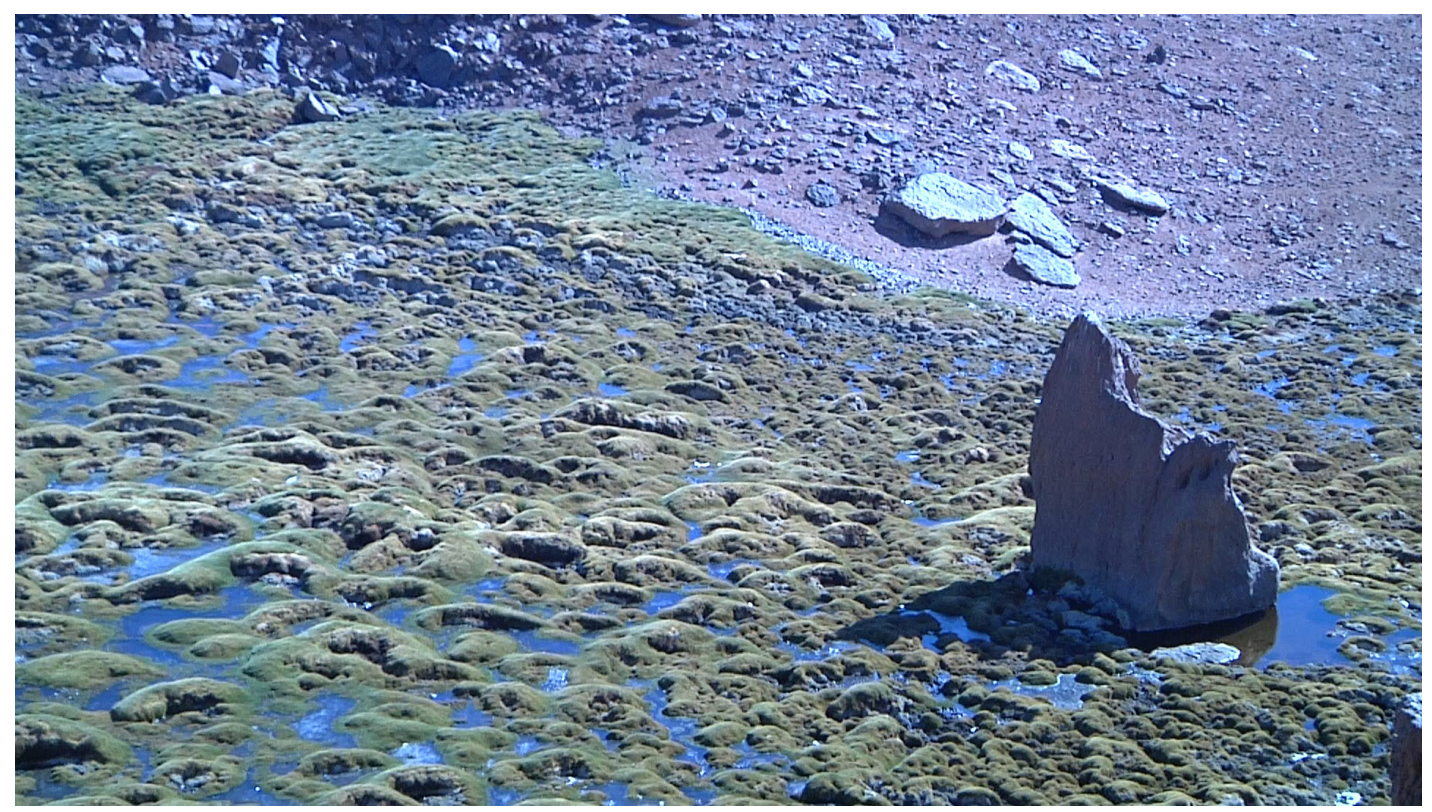

Figura 12. La paskana de Vaquillas, ubicada a $750 \mathrm{~m}$ de las saywas centrales (foto C. Mercado).

The paskana of Vaquillas, located $750 \mathrm{~m}$ from the central saywas (photo C. Mercado).

A unos $40 \mathrm{~m}$ hacia el sur de este sitio, la documentación colonial y arqueológica señala la presencia de cuatro pequeñas "columnas", "mojones" o tupus dispuestos a ambos costados del camino, que describimos en detalle más abajo. Continuando la ruta hacia el portezuelo, el 2017 no identificamos con claridad el camino, pero su proyección mediante las imágenes satelitales más la presencia de cerámica tardía nos permitieron corroborar su asociación al Qhapaq Nan. Ordenados en sentido norte sur, los sitios VA-07, VA-06 y VA-04, confirmaron los reportados por Niemeyer y Rivera (1983), pero además presentaron cerámica Diaguita Inka, Inka y tardía respectivamente (Tabla 1).

Una vez en el portezuelo, cuya altura máxima bordea los $4.400 \mathrm{msm}$, el camino comienza a descender porlafalda sudoccidental deDomeykohaciala Quebrada de Vaquillas, tributaria de ese cordón montañoso. Es decir, se trata de una divisoria de aguas que deslinda naturalmente dos espacios diferentes. Abandonando la zona endorreica de los salares, se inicia a partir de allí un sistema de quebradas y hoyas hidrográficas exorreicas que drenan las faldas cordilleranas en sentido este oeste, inaugurando lo que consideramos un segundo gran trayecto del camino Inka y que abarca alrededor de $275 \mathrm{~km}$ en forma descendente, hasta llegar al Valle de Copiapó. Por sus condiciones ecológicas, este trayecto ofrece mayor acceso a recursos hídricos y forrajeros (Philippi 1860).

\section{Las Saywas de Vaquillas}

El sitio VA-01 presenta dos saywas centrales (VA-01 A y B), además de otras dos estructuras (VA$01 \mathrm{C}$ y D) ubicadas al este y oeste de las anteriores. Las saywas centrales están sobre una pequeña loma aledaña a la Quebrada El Calvario, lo que permite que sean vistas desde el norte a bastante distancia (las otras dos están más lejos entre sí y levemente desplazadas o desalineadas, por lo que al menos en su estado actual no son visibles desde lejos). Aunque en este sector el camino inka no se percibe con claridad en el terreno, las fotos satelitales permiten observarlo con nitidez. Mantiene un rumbo oblicuo noreste sudoeste, y pasa entre ambos hitos centrales que están separados entre sí por $21,7 \mathrm{~m}$. La saywa VA-01-A se emplaza al este del camino y corresponde a un apilamiento con forma de planta cuadrangular cuyas dimensiones son 1,49 $\mathrm{m} x 1,45 \mathrm{~m}$ y un alto de $1,17 \mathrm{~m}$. La saywa VA-01-B está al oeste y consiste en un apilamiento con forma de planta subcircular, con $1,75 \mathrm{~m}$ x 2,3 $\mathrm{m}$ y $1,18 \mathrm{~m}$ de alto. Su mala conservación no permite identificar su forma original, aunque al igual que la otra presenta el característico relleno de piedras más pequeñas en su interior. Estas saywas centrales están asociadas a otros dos apilamientos ubicados al este y oeste respectivamente (VA-01 C y D) que, sin embargo, se encuentran desalineados con respecto a ellas. VA-01-C está a 194 m al este de VA-01-A, y corresponde a una 
estructura con forma de planta irregular y dimensiones de $1,14 \mathrm{~m}$ x 1,07 m x $80 \mathrm{~cm}$ de alto. Su aparejo es rústico y presenta un muro auxiliar de una hilera de piedras en su esquina norte. Por su parte, VA-01-D se ubica a $312 \mathrm{~m}$ al oeste de la estructura VA-01-B, y muestra una planta rectangular con dimensiones de 1,1 $\mathrm{m} \times 1,21 \mathrm{~m}$ y $79 \mathrm{~cm}$ de alto. Como en el caso anterior, actualmente dos pequeños muros de unos $30 \mathrm{~cm}$ de alto se encuentran adosados a su cara sudoeste (Figura 13).

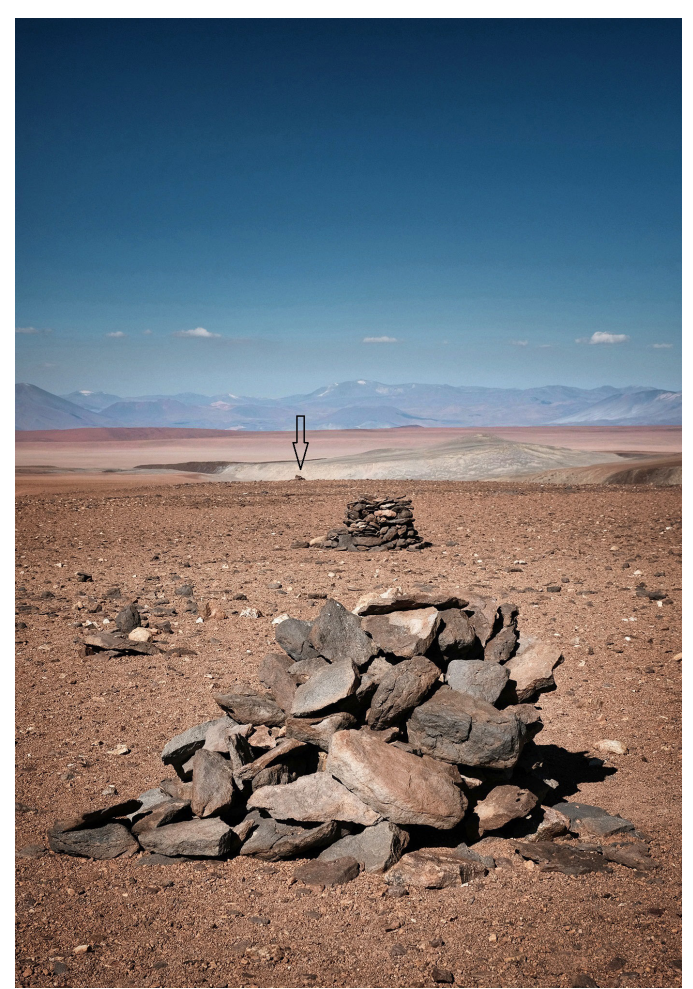

Figura 13. Las dos saywas centrales de Vaquillas. La flecha al fondo indica la saywa semi derrumbada que se ubica más al este, claramente desalineada con las estructuras centrales (foto R. Bennett).

The two central saywas of Vaquillas. The arrow indicates the easternmost, semi-collapsed saywa, clearly misaligned with the central structures (photo R. Bennett).

\section{La frontera inkaica y colonial}

Hacia fines del siglo XVI, las saywas de Vaquillas fueron descritas por primera vez como los hitos o mojones que señalaban una importante frontera inka:

... y para entrar en la provincia [de Chile] se pasa un despoblado de más de 100 leguas, sin agua ni yerba $[\ldots]$ el cual está marcado con los huesos y calaveras de los indios que han muerto por seguir a los españoles. Están en este valle los mojones altos y grandes que dividian las provincias de Chile de las del
Pirú en tiempo de los Ingas (López de Velasco [1574] 1894:518-519) [énfasis nuestro].

Esta cita pertenece al cosmógrafo de la corona, Juan López de Velasco, quien recopiló tempranamente la documentación disponible sobre la geografía del Nuevo Mundo. La certeza de que se trata de Vaquillas proviene de las descripciones y topónimos entregados por los primeros cronistas sobre las aguadas del camino del Despoblado, que permiten reconstruir parte de su derrotero con cierta claridad (Sanhueza 2005, 2012). Pero también se confirma con documentos coloniales y posteriores, que señalan que la localidad continuó siendo un deslinde jurisdiccional importante. En 1744, por ejemplo, la "paskana de Vaquillas" definía el deslinde entre el corregimiento de Atacama y el reino de Chile.

...i en parajes que llaman de las vaquillas, alojamiento o pascana desierta, donde por haber aguada hacen mancion [sic] los que transitan este paraje para el Perú: i en él, para división con la provincia i correjimiento de Atacama, en un cerrito hai dos cruces con que se demarca $i$ comparte este reyno con el pegado o inmediato a dicha cordillera real [énfasis nuestro]. ${ }^{9}$

Las saywas de Vaquillas que se ubican sobre una pequeña meseta, no se mencionan en forma explícita aquí, pero sí en la documentación siguiente, lo que nos permite pensar que muy probablemente las dos saywas centrales fueron las estructuras sobre las cuales se colocaron ambas cruces. Ya se ha dicho que la práctica de poner cruces era común en los hitos de piedra de los caminos o huellas andinas, con el fin de conjurar las expresiones idolátricas. Las saywas de Vaquillas eran sagradas y estaban asociadas al culto al sol, pero también marcaban una frontera colonial. Quizás por eso no fueron destruidas deliberadamente como las de Tocomar, pero sí fueron cristianizadas para legitimar el deslinde. El nombre de la quebrada que está inmediatamente contigua a las saywas (El Calvario) parece confirmar la presencia de cruces en algún período de la historia de Vaquillas, de cuya memoria estaría dando cuenta la toponimia local.

Avanzado el siglo XVIII, las Reales Ordenanzas de 1778 que regulaban el sistema de correos entre Lima y Chile, también mencionan un deslinde colonial en este lugar. En la ruta del Despoblado "a las dos, o tres leguas de Riofrio siguiendo para baquillas se hallan los pirámides [sic], que dividen las jurisdicciones del Reyno del Perú, con el de Chile" (Reales Ordenanzas 1778:161-162) [énfasis nuestro].

Luego de la independencia, durante las negociaciones diplomáticas entre Chile y Bolivia para establecer sus límites en el desierto de Atacama, ésta última incorporó en 
sus alegatos jurídicos el límite señalado por los "mojones del Inga" de Vaquillas (Bertrand 1885; Eyzaguirre 1968). Esto permite contar con información de expediciones chilenas realizadas a la zona para verificar ese deslinde. A mediados del siglo XIX, R.A. Philippi (1860:39) describe detalladamente las saywas de Vaquillas señalando que se trataba de cuatro mojones o "montones de piedra":

Después de haber andado como 4 leguas, desde Río Frío, llegamos a las llamadas 'columnas', que no son columnas como lo indica el nombre sino montones de piedras de unos diez pies de diámetro y 4 1⁄2 pies de alto. Están poco más poco menos de este a oeste, pero no en una línea exacta. Los dos del medio están a distancia de 37 pasos, y el camino pasa entre ellos, los otros distan 200 pasos de ellos (Philippi 1860:39).

Gracias a este antecedente, cuando llegamos al lugar el año 2004, identificamos las cuatro saywas mencionadas (Sinclaire 2004). Como se ha dicho, las dos saywas de los extremos (VA-01 C y D) no son visibles a distancia, y actualmente por estar semiderruidas y muy alteradas resulta difícil identificarlas. Probablemente por esta razón la expedición de Niemeyer y Rivera (1983), que no contaba con esta información, solo identificó tres de estas estructuras. En 1885, el ingeniero A. Bertrand, también en misión oficial, se refería a los hitos de Vaquillas como "las llamadas pirámides" de los documentos coloniales, pero les restaba importancia afirmando que en realidad éstas eran solo "mojones de piedra, como las apachetas de los indios" (Bertrand 1885:289). De manera que las saywas de Vaquillas sobrevivieron en la cartografía oral e incluso administrativa de esa región, para después caer nuevamente en el olvido y en un silencio documental que permaneció hasta las expediciones de los primeros arqueólogos que se internaron por el Despoblado de Atacama.

\section{Equinoccio en Vaquillas}

Nuestra presunción de posibles alineamientos astronómicos de las saywas de distintos puntos del Qhapaq Nan del desierto de Atacama, y en particular de las de Vaquillas, fue confirmada concluyentemente por los astrónomos puesto que su azimut bordeaba los $90^{\circ}$, y por lo tanto estaban orientadas hacia el punto de salida del sol en los equinoccios de otoño y de primavera (21 marzo y 21 de septiembre respectivamente) (Cortés y Martín, Informe Astronómico, en Sanhueza 2012). Finalmente, el amanecer del 21 de marzo de 2017, pudimos presenciar la salida del sol perfectamente alineada con las dos saywas centrales de Vaquillas. Es inevitable señalar que el magnífico espectáculo que ofrece la aurora y luego el despuntar del sol el día del equinoccio es sobrecogedor (Figura 14).

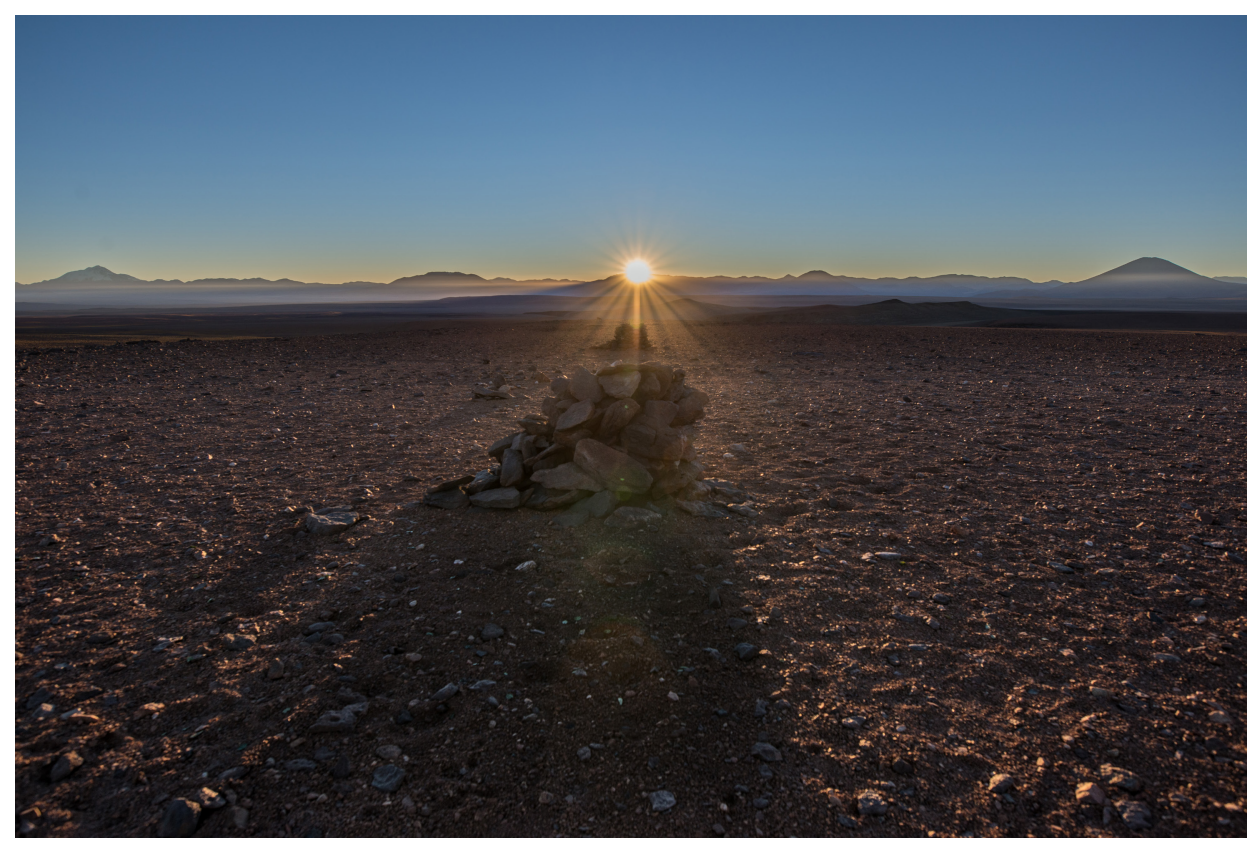

Figura 14. Amanecer del 21 de marzo de 2017, equinoccio de otoño en Vaquillas (foto A. Silber). Sunrise of March 21, 2017, autumn equinox in Vaquillas (photo A. Silber). 
Como se ha dicho, el calendario inkaico se organizaba en torno a dos ciclos opuestos, la estación de lluvias (de diciembre a marzo) y la seca (de abril a noviembre). Los meses de marzo y abril, eran considerados como partes de un mismo ciclo o "mes" conformado por dos períodos opuestos (húmedoseco). El cronista Anónimo [¿1560-1570?] citado por Zuidema y Urton (1976:94) denominaba a este mes Ayriuaquilla y lo asociaba con el equinoccio de otoño, ya que daba inicio al periodo seco y señalaba el momento a partir del cual la presencia del sol comenzaba a disminuir haciéndose los días cada vez más cortos durante los meses siguientes. Ayri, en aymara designa al momento de conjunción de la luna con el sol, es decir cuando la luna pasa entre el Sol y la Tierra (Bertonio 1984:127). Uaquilla o más bien Huaquilla, el segundo componente del nombre del mes, significa yanantin, es decir, unión, pareja, cosas que "siempre van juntas", cosas "hermanadas". Su campo semántico se aplica a los opuestos complementarios que deben ser "igualados" (masculino-femenino, arriba-abajo, etc.), y que "aspiran" a alcanzar el equilibrio y la armonía (Bouysse-Cassagne y Harris 1987; González Holguín 1952:364; Platt 1980).

El equinoccio (del latín aequinoctium, que significa "noche igual"), representa justamente el momento en que los astros opuestos tienen la misma duración, son "iguales". Bertonio (1984:221) define equinoccio entre los aymaras como aromampi urumpi chicasi pacha, que podría traducirse como "tiempo en que la noche y el día son iguales", o en que "se hacen mitades iguales". En esta fecha, los astros opuestos se encuentran (tinku), y logran el equilibrio y el "matrimonio", simbolizado en el principio de yanantin (Bouysse-Cassagne y Harris 1987).

Pero, además, la presencia simbólica del cielo y del calendario que sugerían las fuentes coloniales, especialmente respecto al Llullaillaco, Río Frío y Vaquillas, indica una especial valoración cuzqueña de estos sitios y una estrecha relación no solo con la divinidad solar y el amanecer equinoccial, sino también con otra entidad celeste de gran relevancia en las culturas andinas como el río celeste (Mayu) o la Vía Láctea. La presencia de Mayu en los cielos de Vaquillas aporta a una interpretación más compleja sobre las saywas y sobre la frontera inkaica, e invoca nuevamente el relato del Río Anchallullac o Mentiroso y su relevancia simbólica.

\section{Mayu el río nocturno y el camino del Inka}

Observada desde la tierra, la Vía Láctea experimenta dos tipos de movilidad aparente en el cielo nocturno: a través de la noche (hora a hora) y a través del año (mes a mes), pudiendo reconocérsele periodos de mayor y menor visibilidad. Si se toman como punto de referencia las noches de cada solsticio o equinoccio, la Vía Láctea registra diferentes posiciones y no siempre es visible en su totalidad (Vilches 2005:14-15). Actualmente, los pastores y agricultores atacameños reconocen el ciclo anual del movimiento aparente del sol y lo complementan con la observación nocturna del cielo, donde adquieren protagonismo la luna, los luceros y la Vía Láctea (Cruz et al. 2013). Los sectores de pampas o planicies de altura facilitan la observación del río celeste, por eso la amplia visibilidad que ofrece el Despoblado de Atacama parece haber incidido también en la importancia otorgada por los inkas a Mayu en la región. La Vía Láctea es percibida como una entidad que tiene una estrecha relación con los ciclos vitales de la naturaleza y en especial con los ciclos del agua, por lo que la observación de su movimiento aparente permite complementar el calendario productivo y sus rituales asociados (Cruz et al. 2013; Urton 2006). En el hemisferio sur, la Vía Láctea se presenta como una gran franja luminosa que atraviesa la bóveda del cielo, en una posición inclinada norte sur y este oeste. Desde la mirada andina, al salir el sol Mayu se sumerge en el horizonte y desaparece de la vista, para renacer al siguiente anochecer y volver a circular. Además, en su movimiento aparente, no solo oscila en una diagonal este oeste, sino que además invierte su curso cada 12 horas, corriendo en sentido contrario (Urton 2006). Esta perspectiva, aporta nuevos significados a la interpretación de los relatos sobre el Río Anchallullac del Despoblado de Atacama. Si observamos al río celeste durante la noche del equinoccio de marzo en Vaquillas, podemos apreciar como en esta fecha adquiere muy buena visibilidad, y se pueden observar con bastante claridad las constelaciones negras, en las que los pueblos andinos distinguían a la Llama (Yakana), la cría de la llama (Uñallamacha), la Perdiz (Yutu), entre otras divinidades (Urton 2006) (Figura 15). Por otra parte, esta imponente presencia visual del río nocturno adquiere más sentido o significado en la citada referencia del siglo XVI sobre la frontera inkaica, al vincular al Río Anchallullac con el camino, con las saywas, y con el cielo nocturno de Vaquillas:

Están en este valle los mojones altos y grandes que dividían las provincias de Chile de las del Pirú en tiempo de los Ingas y en medio del un arroyo pequeño que se dice Auchillulca [sic], que quiere decir "muy mentiroso", porque a ciertas horas del día llega el agua dél al camino real del Inga... (López de Velasco 1894 [1574]:518-519) [énfasis nuestro].

Este relato parece estar recogiendo - sin saberlouna voz y una mirada indígena que está representando y ritualizando un evento astronómico significativo. Una lectura más fina de esta tradición oral nos sugiere que 


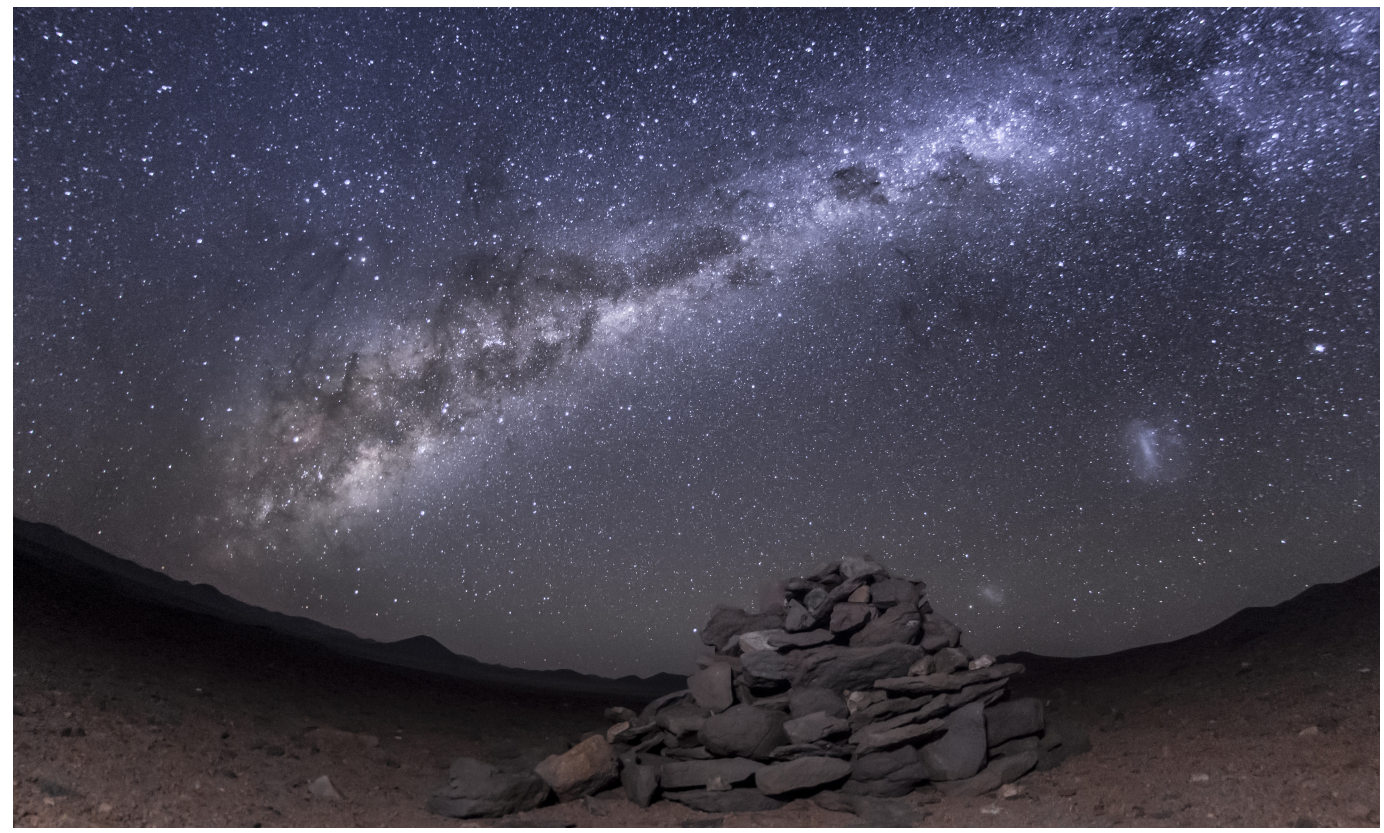

Figura 15. La Vía Láctea en la madrugada del día equinoccial en Vaquillas donde se aprecia con bastante claridad la Yakana, y los demás seres que habitan el río celeste (foto A. Silber).

The Milky Way in the early morning of the equinoctial day in Vaquillas, where the Yakana and the other gods that inhabit the celestial river can be seen quite clearly (photo A. Silber).

hay un estrecho vínculo simbólico entre el Qhapaq Ñan, las saywas, Inti, Mayu, el Río Alchallullac, y el volcán y santuario inka del Llullaillaco (Llulla Yacu), lo que parece otorgar a esta región un estatus privilegiado dentro de la geografía sagrada del Tawantinsuyu.

Por otra parte, hemos propuesto y discutido anteriormente (Sanhueza 2005, 2012) la posible asociación que había entre el nombre de este mes (Huaquilla) y el topónimo castellanizado Vaquillas. Por razones de espacio no lo desarrollamos aquí, pero queremos destacar que las relaciones dialécticas que encierran estos elementos simbólicos se condicen con el concepto andino de frontera como lugar de oposición y de encuentro de contrarios (tinku), y como lugar de equilibrio (yanantin). Desde esa mirada, la frontera terrestre parece haber sido un reflejo del espacio celeste y de la dinámica cíclica de oposiciones y encuentros entre los astros divinizados.

Pero las saywas de la frontera de Vaquillas no solo dialogaban con el cielo. También marcaban presencia y construían paisaje desde el camino del Inka. Como puede apreciarse, el deslinde sacralizado de Vaquillas marcaba un límite y un punto de transición simbólica a través de una composición simétrica del paisaje. El portezuelo, anunciado desde la distancia por los "mojones del Inga", señalaba un hito relevante del camino y se representaba como una puerta (punku) hacia otro espacio y hacia otro campo visual. Después del abra comenzaba el descenso hacia otro ambiente ecológico algo más benigno. Pero, además, luego de atravesar el portezuelo desaparecía de la vista la presencia dominante del volcán y wak'a inkaica del Llullaillaco (Figura 16).

\section{Discusión y conclusiones}

\section{Vaquillas. Frontera y calendario}

Como se trató y discutió en otras publicaciones (Sanhueza 2005, 2012), el cambio ecológico que se registra a partir del sur de Vaquillas no está asociado solo a particularidades o microclimas locales. Obedece principalmente a importantes cambios climáticos provocados por la influencia contrapuesta de los dos grandes sistemas pluviales que regulan las lluvias en Sudamérica. Los monzones de verano, provenientes de la Amazonía, se desplazan hacia las tierras altiplánicas expandiéndose luego hacia las vertientes occidentales de los Andes, ejerciendo un predominio de las lluvias de verano (entre diciembre y marzo). Por su parte, desde el suroeste provienen las húmedas masas de aire 


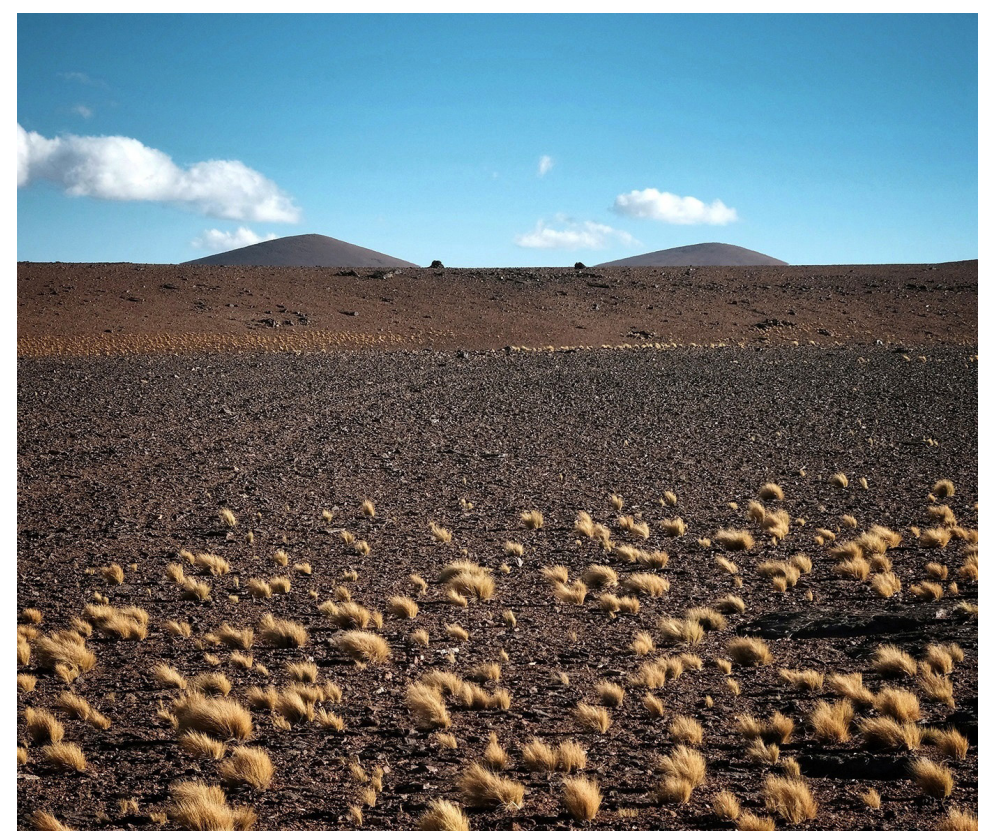

Figura 16. Vista norte sur de las saywas de Vaquillas desde el camino inka, que anuncia el acceso al abra y a la frontera sagrada (foto F. Vilches).

North-south view of the saywas of Vaquillas from the Inca trail, which announces the access to the open and the sacred border (photo F. Vilches).

del Pacífico que dominan los patrones de pluviosidad en el centro y sur de Chile, imponiendo un régimen de precipitaciones de invierno (de junio a septiembre). En la actualidad esta zona de transición coincide en parte con el Parque Nacional Llullaillaco, que se extiende aproximadamente entre las latitudes $24^{\circ} 30^{\prime} \mathrm{S}$ y $25^{\circ} 15^{\prime}$ $\mathrm{S}$, es decir, en el espacio fronterizo que hemos estado analizando. Incluso, según algunos autores, el límite sur de estas influencias -ya con escasas e irregulares lluvias estivales- se produce en la Precordillera de Domeyko (Betancourt et al. 2000:1542).

Es decir, el Volcán Llullaillaco y nuestra zona de estudio, se sitúan en un espacio de transición e intersección entre el sistema de lluvias intertropicales de verano, conocido como "invierno altiplánico" o "boliviano", y el de precipitaciones extratropicales de invierno o "invierno chileno" (Maldonado et al. 2005). Según estudios paleobotánicos, un efecto visible de estos cambios se manifiesta en la flora local, puesto que el límite sur de la mayoría de las plantas que florecen en verano (diciembre/marzo) alcanza los $24^{\circ}$, mientras que a partir de los $25^{\circ}$ comienzan a florecer plantas propias del régimen pluvial de invierno, coincidentemente con la latitud de la paskana y saywas de Vaquillas $\left(25^{\circ} 11^{\prime}\right)$ (Betancourt et al. 2000:1542). Desde una perspectiva continental más amplia, la cuenca del Salar de Punta Negra y el Portezuelo de Vaquillas corresponden a una importante frontera climática y biogeográfica que dibuja una línea virtual en el espacio, conocida como la "Diagonal Árida de Sudamérica". Esta frontera virtual, que abarca desde el sureste argentino hasta el noroeste del Perú, divide el dominio de las lluvias de verano hacia el noreste, y de la pluviosidad de invierno hacia el suroeste en una inmensa extensión. En el Despoblado de Atacama su trazado imaginario pasa justamente por la cumbre del Volcán Llullaillaco, estableciendo un espacio de transición biogeográfica que debe adaptarse a las lluvias de verano tanto como a las lluvias de invierno (Garleff et al. en Maldonado et al. 2005:493) (Figura 17). En definitiva, esta frontera natural se sitúa en un espacio de límite, de encuentro, de articulación y de oposición entre ambos regímenes climáticos continentales (Maldonado et al. 2005:495).

Desde esa mirada, las tradiciones orales, el adoratorio del Llullaillaco, la toponimia, las saywas de Tocomar, la Quebrada de Río Frío (Anchallullac), y las saywas del Portezuelo de Vaquillas permiten proponer una interpretación de los significados otorgados por el Tawantinsuyu a esta región del Despoblado de Atacama. Estos hitos sagrados podrían estar dando cuenta de los confines de un espacio más amplio, o de los inicios de un territorio de transición en el que se produce una inversión del tiempo de las lluvias, una inversión de la organización del calendario anual, de sus rituales y fiestas asociadas, y sobre todo una inversión del discurso temporal, espacial y cosmológico 


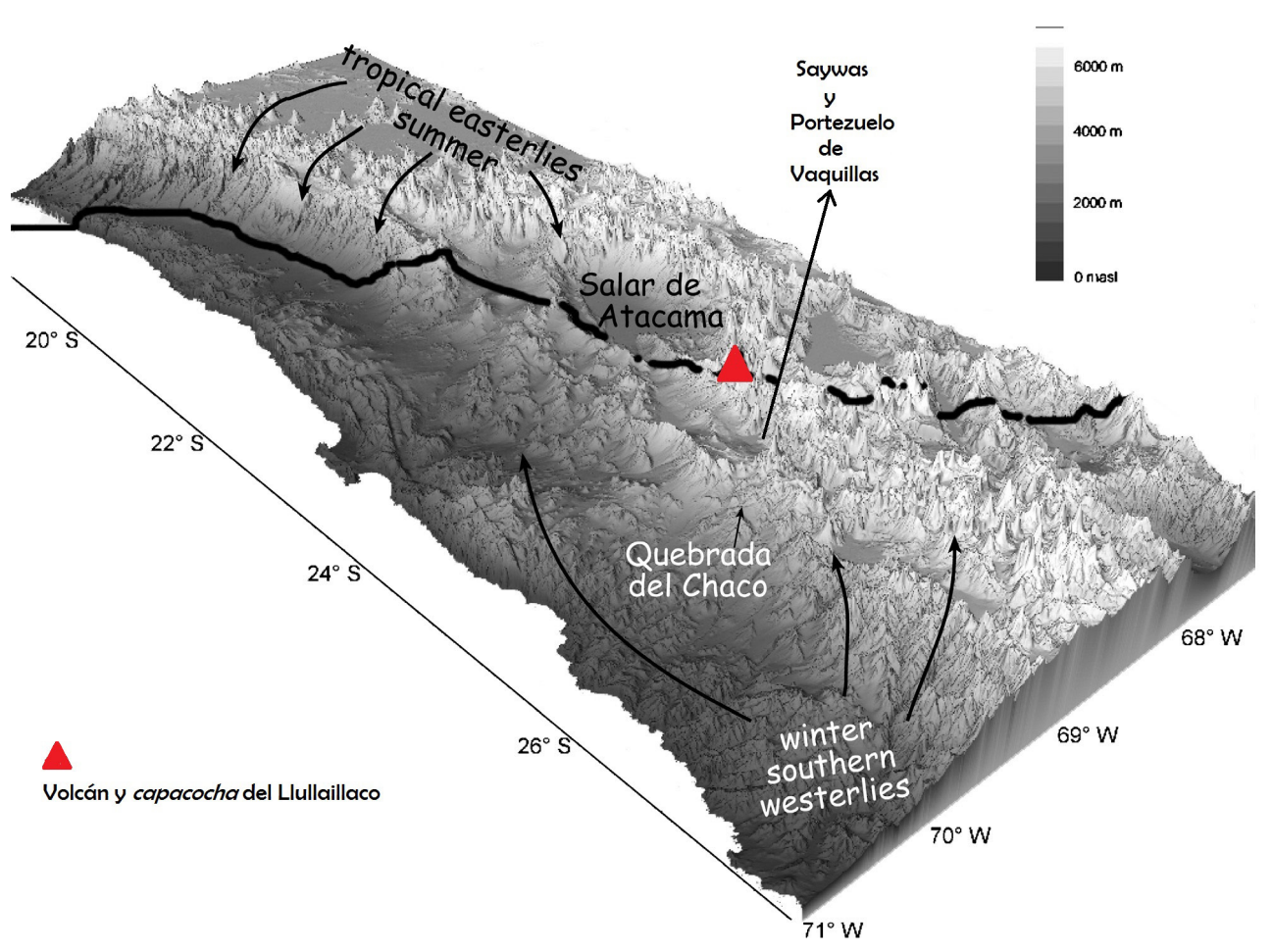

Figura 17. La Diagonal Árida de Sud América es la línea imaginaria que señala la frontera entre los dos grandes sistemas climáticos que regulan las estaciones de lluvias a través de Sudamérica (mapa hecho en base a publicación de Maldonado et al. 2005).

The Arid Diagonal of South America is the imaginary line that marks the border between the two great climatic systems that regulate the rainy seasons throughout South America (map based on publication by Maldonado et al. 2005).

del Estado inkaico (Sanhueza 2005, 2012). En este sentido, la localidad de Vaquillas parece haber sido entendida simbólicamente como el punto liminal de un espacio y un tiempo en el que los meses de marzo y abril y el equinoccio de otoño, representaban el término de un ciclo (temporada de lluvias) y el inicio de otro (temporada seca). Posiblemente, a partir de allí el orden del mundo andino comenzaba a diluirse, o incluso a desintegrarse, inaugurando hacia el sur un calendario compuesto por ciclos productivos y rituales distintos y opuestos. Desde esa perspectiva podemos preguntarnos si los topónimos Llullaillaco "aguas mentirosas", y Anchallullac, río "muy mentiroso", no tendrían entre sus varios significados alguna relación con la situación "engañosa" que puede provocar un calendario de lluvias "invertido".

Otro punto a considerar es el hecho de que el paisaje orográfico en el portezuelo y después de él, cambia significativamente. Como se ha dicho, el camino comienza a descender y continúa atravesando numerosas quebradas que corren en sentido este oeste, pero que ya no pertenecen a los Andes sino a la Cordillera de Domeyko. El cordón de Domeyko, que se había ido desplazando o cerrando hacia el oriente para finalmente anteponerse en forma paralela al macizo andino, se yergue ahora al oriente del camino del Inka $y$, en ese sentido, se puede observar que el sistema orográfico de esta frontera también se ha invertido. Sin embargo, si éste es el caso de Vaquillas ¿qué podrían estar deslindado las saywas de Tocomar ubicadas a unos $85 \mathrm{~km}$ más al norte?

Pensamos que las saywas de Tocomar al norte y de Vaquillas al sur, podrían estar delimitando simbólicamente un sector de honda significación como el espacio de dominio visual del Llullaillaco, o de la presencia gravitante del Río Mentiroso, de la Vía Láctea y de la divinidad solar. De hecho, Río Frío se origina en la Cordillera de Domeyko, relativamente cerca de las saywas de Vaquillas, y drena al Salar de Punta Negra en un punto muy próximo a las saywas de Tocomar. Esto permite abordar conceptualmente la importancia simbólica del agua en la zona, que pareciera integrar este espacio a través de un eje acuático que unía o enlazaba los ojos de agua del entorno de Tocomar con Río Frío, y a éste con la paskana de El Calvario, en Vaquillas. Sin embargo, es preciso recordar también que el punto alto del Portezuelo de Vaquillas marca otro límite geográfico natural importante, puesto que ahí se produce el divorcio de aguas entre ambas vertientes de la Cordillera de Domeyko. Como destaca Philippi, en 
el siglo XIX las columnas de Vaquillas no se ubican en el portezuelo mismo (están unos 6 o $7 \mathrm{~km}$ más abajo, o más al norte), por lo que concluye que este límite territorial no obedecía a ningún accidente natural que justificara su ubicación precisa (Philippi 1860:39). Por lo que hemos planteado, esta observación no es menor ipor qué las saywas se sitúan ahí y no más arriba, en el límite natural? Posiblemente el acceso a agua en la quebrada del Calvario fue una de las razones concretas no solo para emplazar ahí las saywas sino también para ofrendar desde tiempos preinkaicos alfarería decorada y challado de mineral de cobre en las estructuras o refugios vecinos a la paskana (VA-02).

La tradicional práctica inkaica de "ordenar" el territorio, amojonando las provincias sometidas y los recursos disponibles para el estado, se expresa en innumerables fuentes coloniales (Sanhueza 2004). Incluso está presente en esta región, donde no había poblados permanentes, sino que era ocupada en forma transitoria por quienes recorrían o explotaban estacionalmente sus recursos mineros, salinos, pastoriles, de caza y de recolección. Según el cronista Martín de Murúa, fue especialmente Tupac Inka Yupanqui quien habría amojonado "toda la tierra con gran orden y cuenta", estableciendo los deslindes "conforme a las corrientes de los ríos", es decir aplicando el criterio también occidental del divortia aquarum, pero otorgándole significados de diferente complejidad simbólica y ritual. Además, sabemos que el Inka amojonó "todo género de minas, [a]sí de oro como de plata y demás metales", y puso límites en las salinas o salares y en otras fuentes de recursos naturales (Murúa 1987:370). Según Bernabé Cobo "también estaban amojonados los cazaderos y cotos del ganado bravo y silvestre, como eran guanacos, vicuñas y venados". Incluso, señala que "hizo el Inca todos los cazaderos realengos y propios suyos, de manera que ninguno podía cazar en ellos sin licencia suya o de sus gobernadores" (Cobo 1964 [1956]:122-123).

Es decir, los deslindes de Tocomar y de Vaquillas independientemente de otros posibles significados, pudieron responder también a criterios de este tipo. De hecho, en el Despoblado de Atacama la actividad minera inkaica fue relevante, como es el caso de la Mina Las Turquesas, ubicada cerca de El Salvador en la actual Región de Atacama (González Godoy et al. 2017) ${ }^{10}$. A su vez, el Despoblado de Atacama se caracterizó siempre por la especial buena calidad de la lana de sus vicuñas. De ser así, el territorio en estudio bien pudo haber sido amojonado para resguardar determinados enclaves mineros, o el hábitat de fauna silvestre de alta valoración como la vicuña.

El territorio que abarca el camino inka de la cuenca del salar de Punta Negra se inserta en un espacio mayor también conquistado por el Inka. Es decir, corresponde a una especie de "ínsula inkaica" (sensu Morris 1998), en el sentido planteado por Berenguer (2007:435), que propone entender la expansión imperial como una política territorialmente discontinua, y que por tanto va estableciendo una serie de "fronteras internas" que consistirían en bordes activos que limitarían otros territorios menores dentro del Tawantinsuyu.

Agradecimientos: a MineraEscondida, que financió el proyecto del Museo Chileno de Arte Precolombino "Navegantes en el desierto: cuando el cielo se inscribe en el camino", a Carlos Aldunate (MChAP), Claudio Mercado (MChAP), Ralph Bennett (Alma), Jorge Vega (CONAF), Marinka Núñez, Pablo Mignone, Carole Sinclaire, Lautaro Núñez, Mario Pereira, Flora Vilches, Willy Faúndez, Sebastián Larraín, Guy Wenborne. Por último, va nuestro especial reconocimiento a los evaluadores de este trabajo, cuyos aportes fueron sustantivos para el enriquecimiento y claridad del texto original.

\section{Referencias Citadas}

Advis, P. 2008. El Desierto Conmovido. Paso de la Hueste de Almagro por el Norte de Chile. Universidad Arturo Prat, Iquique.

Bauer, B. y D. Dearborn 1998. Astronomía e Imperio en los Andes. Centro de Estudios Regionales Andinos Bartolomé de Las Casas, Cuzco.

Berenguer, J. 2004. Cinco milenios de arte rupestre en los Andes atacameños: Imágenes para lo humano, imágenes para lo divino. Boletín del Museo Chileno de Arte Precolombino 9:75-108.

Berenguer, J. 2007. El Camino Inka del Alto Loa y la creación del espacio provincial en Atacama. En Producción y Circulación Prehispánica de Bienes en el Sur Andino, compilado por A. Nielsen, C. Rivolta y V. Seldes, pp. 413-435. Editorial Brujas, Córdoba.

Berenguer, J., I. Cáceres, C. Sanhueza y P. Hernández 2005. El Qhapaqnan en el Alto Loa, norte de Chile: un estudio micro y macromorfológico. Estudios Atacameños 29:7-39.

Berenguer, J. y D. Salazar 2017. Incaguasi, "donde dormían las carretas". Arqueología de un lugar de paso en el valle del Alto Loa, desierto de Atacama. Estudios Atacameños 56:163-195.
Bertonio, L. 1984 [1612]. Vocabulario de la Lengua Aymara. Ediciones Ceres, Cochabamba.

Bertrand, A. 1885. Memoria sobre las Cordilleras del Desierto de Atacama i Regiones Limitrofes, Presentada al Señor Ministro del Interior. Imprenta Nacional, Santiago.

Bouysse Cassagne, T. y O. Harris 1987. Pacha: en torno al pensamiento aymara. En Tres Reflexiones sobre el Pensamiento Andino. HISBOL, La Paz.

Betancourt, J.L., C. Latorre, J.A. Rech, J. Quade y K.A. Rylander 2000. A 22,000-year record of moonsonal precipitation from northern Chile's Atacama Desert. Science 289:1542-1546.

Castro, V. y V. Varela 2004. De cómo camina el sol durante junio, de lo que se ve en el cielo y de lo que se comenta y se practica en la tierra. Oralidad y rituales en la subregión del Río Salada, Norte de Chile. En Etno y Arqueo-astronomía en las Américas, editado por M. Boccas, J. Broda y G. Pereira, pp. 285-298. Congreso Internacional de Americanistas, Santiago. 
Castro, V., V. Varela, C. Aldunate y E. Araneda 2004. Principios orientadores y metodología para el estudio del Qhapaqñan en Atacama: desde el Portezuelo del Inka hasta Río Grande. Chungara Revista de Antropología Chilena 36 (2):463-481.

Cobo, B. 1964 [1956]. Historia del Nuevo Mundo. Biblioteca de Autores Españoles, T. XCII, vol.II. Ediciones Atlas, Madrid.

Cruz, J., J. Cortés, C. Yufla y N. Henríquez 2013. El Universo de Nuestros Abuelos. Proyecto de Etnoastronomía Atacameña. Observatorio Alma, Universidad Católica del Norte, Antofagasta.

De Souza, J.L. 2008. A (in)visibilidade dos lugares kadiwéu: contribuições da geografia cultural para o estudo de populações indígenas. Espaço e Cultura 23:53-66.

Dirección Regional de Comercio Exterior y Turismo Amazonas (DIRCETUR Amazonas). http://www.facebook.com/media/ set $/$ set $=$ a. $252999188108270.59903 .181980711876785 \&$ type $=3$ (15 abril 2012).

Eyzaguirre, J. 1968. Breve Historia de las Fronteras de Chile. Editorial Universitaria, Santiago.

Figueroa,V.,A. Mezies yP. Sapiains 2018. Estudioarqueomineraológico de los minerales de cobre del Tambillo de Tocomar, salar de Punta negra, Región de Antofagasta, Chile. Informe Técnico Proyecto: Navegantes del desierto: cuando el cielo se inscribe en el camino (Escondida, Mchap y Alma). Presentado en el Museo Chileno de Arte Precolombino.

Garcilaso de la Vega, I. 1995 [1604]. Comentarios Reales de los Incas. Tomos I y II, edición, índice analítico y glosario de Carlos Araníbar. Fondo de Cultura Económica, México DF.

Gedda, F. 1995. La ruta de la turquesa. Programa Al Sur del Mundo. https://www.youtube.com/watch?v=p6MTCQ3c6n4 (5 de noviembre de 2018).

González Godoy, C. 2017. Arqueología vial del Qhapaq Ñan en Sudamérica: Análisis teórico, conceptos y definiciones. Boletín del Museo Chileno de Arte Precolombino 22 (1):15-34.

González Godoy, C. y C. Westfall 2005. Consideraciones sobre la prehistoria de Atacama: El Salvador y sus aportes locales e interregionales. Boletín Sociedad Chilena de Arqueología 38:53-70.

González Godoy, C., C. Westfall y C. Castells 2017. Mina Las Turquesas: Lapidaria, secuencia alfarera prehispánica e interrelaciones culturales en un espacio internodal del Desierto de Atacama, Chile. Estudios Atacameños 56:225-251.

González Holguín, D. 1952 [1608]. Vocabulario de la Lengua de Todo el Perú Llamada Lengua Qqichua o del Inca. Universidad Nacional de San Marcos, Lima.

Guaman Poma de Ayala, F. 1992 [1614]. Nueva Corónica y Buen Gobierno. Editado por J. Murra y R. Adorno. Siglo XXI Editores, México, DF.

Hyslop, J. 1984. The Inka Road System. Academic Press, Orlando.

López de Velasco, J., 1894 [1571-1575]. Geografía y descripción universal de las Indias recopiladas por el cosmógrafo cronista desde el año 1571 al 1575, con adiciones e ilustraciones por D. Justo Zaragoza. Establecimiento Tipográfico de Fortanet, Madrid.

Lynch, T. 1995-96. Inka roads in the Atacama: effects of later use by mounted travelers. Diálogo Andino 14/15:187-203.

Lynch, T. y L. Núñez 1994. Nuevas evidencias inkas entre Kollahuasi y Río Frío (I y II regiones del norte de Chile). Estudios Atacameños 11:145-164.
Maldonado, A., J. Betancourt, C. Latorre y C. Villagrán 2005. Pollen analyses from a 50000-yr rodent middens series in the Southern Atacama Desert (25 30'S). Journal of Quaternary Science 20 (5):497-507

Molina, R. 2018. La mirada del chasqui: recorriendo el camino incaico entre la sierra de Arica y Copiapó. En Qhapaq NanAtacama. Trazado Visual al Camino del Inca en su Paso por el Desierto. LOM Ediciones, Santiago.

Morris, C. 1998. Más allá de la frontera de Chincha. En La Frontera del Estado Inca, editado por T. Dillehay y P. Netherly, pp. 106-113. Fundación Alexander Von Humboldt/Editorial Abya-Yala, Quito.

Murúa, M. de 1987 [1613]. Historia General del Perú. Historia 16, editado por M. Ballesteros, Madrid.

Murúa, M. de 2004 [1615]. Códice Murúa: Historia y Genealogía de los Reyes Incas del Perú del Padre Mercedario Fray Martín de Murúa. Códice Galvin, estudio y edición de J. Ossio. Testimonio Compañía Editorial, Madrid.

Niemeyer, H. y M. Rivera 1983. El Camino del Inca en el Despoblado de Atacama. Boletín de Prehistoria de Chile 9:91193.

Núñez, P. 1981. El Camino del Inca. Creces 10 (2):49-57.

Philippi, R.A. 1948 [1853]. Exploración del desierto de Atacama. En Revista Chilena de Historia y Geografía 112:193-224.

Platt, T. 1980. El concepto de Yanantin entre los Machas de Bolivia. En Parentesco y Matrimonio en los Andes, editado por E. Mayer y R. Borton, pp. 139-182. Pontificia Universidad Católica del Perú, Lima.

Reales Ordenanzas 1778. Instrucciones y Reglamentos Apropiados para el Gobierno y Manejo de la Renta de Estafetas, Correos y Postas del Reyno del Perú y Chile, 1778. Madrid.

Reinhard, J. y C. Ceruti 2000. Investigaciones Arqueológicas en el Volcán Llullaillaco. Complejo Ceremonial Incaico de Alta Montaña. Editorial de la Universidad Católica de Salta, Salta.

Salinas, M. 1863. Impugnación a la Cuestión de Límites entre Chile y Bolivia escrita por Miguel L. Amunátegui. Tipografía de Pedro España, Sucre.

Sanhueza, C. 2004. Medir, amojonar, repartir: Territorialidades y prácticas demarcatorias en el camino incaico de Atacama (II Región, Chile). Chungara Revista de Antropología Chilena 36 (2):481-492.

Sanhueza, C. 2005. Espacio y tiempo en los límites del mundo. Los incas en el despoblado de Atacama. Boletín del Museo Chileno de Arte Precolombino 10 (2):51-77.

Sanhueza, C. 2012. Las Sayhuas del Inca. Territorio, Frontera, Geografía Sagrada y Cartografía Oral en el Desierto de Atacama. Tesis para optar al grado de Doctora en Historia, Mención Estudios Andinos, Escuela de Posgrado, Pontificia Universidad Católica del Perú, Lima.

Sanhueza, C. 2017. Las saywas del Inka en el desierto de Atacama: ¿Una inscripción del calendario en el Qhapaq Nan? Boletín del Museo Chileno de Arte Precolombino 22 (2):133-152.

Santo Tomás, D. 1951 [1560]. Lexicón. Edición Facsimilar. Instituto de Historia, Universidad Nacional de San Marcos, Lima.

Sarmiento de Gamboa, P. 1942 [1572]. Historia de los Incas. Colección Hómeo, Emecé Editores, Buenos Aires.

Sinclaire, C. 2005. Ocupaciones prehispánicas e históricas en las rutas del Despoblado de Atacama. Informe Anual Proyecto Fondecyt 1040290. 
Sinclaire, C. 2006. Descripción tramos del Camino del Inka y recintos asociados entre Río Frío y Puquios. Cuencas intermontanas al sur del Salar de Atacama. Informe Final, Proyecto Fondecyt 1040290.

Urton, G. 2006. En el Cruce de Rumbos de la Tierra y el Cielo. Centro de Estudios Regionales Andinos Bartolomé de Las Casas, Cuzco.

Vilches F. 2005. Espacio celeste y terrestre en el arte rupestre de Taira. Boletín del Museo Chileno de Arte Precolombino 10 (1):9-34.
Vivar, J. 1988 [1558]. Crónica de los reinos de Chile. Historia 16, editado por A. Barral Gómez, Madrid.

Zecenarro, G. 2001. Arquitectura arqueológica en la quebrada de Thanpumachay, Municipalidad del Cuzco, Cuzco.

Zuidema, T. y G. Urton 1976. La constelación de la llama en los Andes peruanos. Allpanchis 9:59-119.

\section{Notas}

${ }^{1}$ Las saywas pueden ser definidas en forma genérica como estructuras de base cuadrada, rectangular, o indeterminada, que pueden alcanzar $1,20 \mathrm{~m}$ de altura, pero cuyo tamaño original pudo ser mayor. Están construidas por superposición de piedras, aunque obedecen a una planificación previa y, frecuentemente, contienen un relleno interior de piedras más pequeñas. Se pueden encontrar en parejas (una a cada lado del camino), o en número de cuatro o más, dibujando una línea que atraviesa el camino. Sin embargo, el alineamiento de las saywas de los extremos no es exacto con respecto a las dos estructuras centrales. Sólo estas últimas son, hasta el momento, el referente astronómico. La razón de esto está todavía en estudio.

${ }^{2}$ La fuente de basalto más cercana está en Morro Punta Negra (TO-01), casi a orillas del salar, y pese a que no se pudo confirmar la existencia allí del lugar de manufactura de los gnómones, la probabilidad de que la evidencia de ello se encuentre sepultada por la arena es relativamente alta.

${ }^{3}$ El itinerario del sol luego de asomarse en el horizonte se aprecia como una línea ascendente diagonal y no vertical. Es decir, si no tenemos obstáculo en el horizonte, el día del solsticio de invierno el sol saldrá a $64^{\circ}$. Pero si hay una loma, éste se desplazará un poco hacia el norte antes de hacerse visible. Mientras más grande y más cerca esté la montaña, más diferencia existirá entre el horizonte teórico y el real.

${ }^{4}$ Lamentablemente, desconocemos su nombre original en kunza $\mathrm{u}$ otras lenguas de regiones vecinas. Respecto al río, en quechua,
Ancha significa "muy" o "mucho" y Llullaq, "mentira", "engaño" (González Holguín 1952).

${ }^{5}$ Este departamento se ubica en el noreste peruano, en el espacio de transición entre la cordillera andina y la llanura amazónica, y limita al norte con la frontera del Ecuador.

${ }^{6}$ La posibilidad de que una aguada crezca repentinamente producto de las escasas, pero intensas lluvias estivales, puede darse en cualquier lugar del desierto de altura. Sin embargo, el relato asociado a Río Frío da cuenta de un evento que se produce todos los días o noches, según las distintas versiones.

${ }^{7}$ La expedición de Al sur del Mundo (Gedda 1995: minutos 21:07 a 27:04), es muy útil para apreciar varias de las estructuras registradas por esos investigadores 15 años antes, incluyendo las columnas (saywas) de Vaquillas.

${ }^{8}$ El verbo paska, "desatar"o "desamarrar" en quechua, se asocia hasta la actualidad con la paskana, el lugar de la ruta donde se puede soltar a los animales para que se alimenten.

9 "Relación del Obispado de Santiago y del Reino de Chile.... en cumplimiento de Real Orden de 18 de Julio de 1729". Documento citado en Salinas (1863:73-74)

${ }^{10}$ Es sugerente que en lengua quechua una mina de cobre se denomina "anta chacra" (anta: cobre, chacra: cultivo o sementera) (González Holguín 1952). Esto indica que en ciertas etnotaxonomías andinas, las vetas de este mineral no son algo inerte, sino orgánico, que crece y se cultiva como simiente. Desde esta mirada, este tipo de mineral necesita ser "regado" como cualquier chacra (Berenguer 2004:105, nota 10$)$. 